\title{
ITRAQ-based quantitative proteomic analysis of processed Euphorbia lathyris L. for reducing the intestinal toxicity
}

Yu Zhang ${ }^{1}$, Yingzi Wang ${ }^{1 *}$, Shaojing $\mathrm{Li}^{2^{*}}$, Xiuting Zhang ${ }^{1}$, Wenhua Li ${ }^{1}$, Shengxiu Luo ${ }^{1}$, Zhenyang Sun ${ }^{1}$ and Ruijie $\mathrm{Nie}^{1}$

\begin{abstract}
Background: Euphorbia lathyris L., a Traditional Chinese medicine (TCM), is commonly used for the treatment of hydropsy, ascites, constipation, amenorrhea, and scabies. Semen Euphorbiae Pulveratum, which is another type of Euphorbia lathyris that is commonly used in TCM practice and is obtained by removing the oil from the seed that is called paozhi, has been known to ease diarrhea. Whereas, the mechanisms of reducing intestinal toxicity have not been clearly investigated yet.

Methods: In this study, the isobaric tags for relative and absolute quantitation (iTRAQ) in combination with the liquid chromatography-tandem mass spectrometry (LC-MS/MS) proteomic method was applied to investigate the effects of Euphorbia lathyris L. on the protein expression involved in intestinal metabolism, in order to illustrate the potential attenuated mechanism of Euphorbia lathyris L. processing. Differentially expressed proteins (DEPs) in the intestine after treated with Semen Euphorbiae (SE), Semen Euphorbiae Pulveratum (SEP) and Euphorbiae Factor 1 $\left(\mathrm{EFL}_{1}\right)$ were identified. The bioinformatics analysis including $\mathrm{GO}$ analysis, pathway analysis, and network analysis were done to analyze the key metabolic pathways underlying the attenuation mechanism through protein network in diarrhea. Western blot were performed to validate selected protein and the related pathways.

Results: A number of differentially expressed proteins that may be associated with intestinal inflammation were identified. They mainly constituted by part of the cell. The expression sites of them located within cells and organelles. G protein and Eph/Ephrin signal pathway were controlled jointly by SEP and SE. After processing, the extraction of SEP were mainly reflected in the process of cytoskeleton, glycolysis and gluconeogenesis.

Conclusions: These findings suggest that SE induced an inflammatory response, and activated the Interleukin signaling pathway, such as the Ang/Tie 2 and JAK2/ STAT signaling pathways, which may eventually contribute to injury result from intestinal inflammatory, while SEP could alleviate this injury by down-regulating STAT1 and activating Ang-4 that might reduce the inflammatory response. Our results demonstrated the importance of Ang-4 and STAT1 expression, which are the target proteins in the attenuated of SE after processing based on proteomic investigation. Thus iTRAQ might be a novel candidate method to study scientific connotation of hypothesis that the attenuated of SE after processing expressed lower toxicity from cellular levels.
\end{abstract}

Keywords: Euphorbia lathyris, Proteomics, iTRAQ, Bio-pathway

\footnotetext{
* Correspondence: wangyzi@sina.com; shaojingli2004@126.com

${ }^{1}$ College of Traditional Chinese Pharmacy, Beijing University of Chinese Medicine, North Third Ring Road, Number 11, Chaoyang District, Beijing 100029, People's Republic of China

${ }^{2}$ Institute of Chinese Materia Medica, China Academy of Chinese Medical Sciences, Dong cheng District, Dongzhimen Neixiang Street on the 16th, Beijing 100700, People's Republic of China
}

(c) The Author(s). 2018 Open Access This article is distributed under the terms of the Creative Commons Attribution 4.0 International License (http://creativecommons.org/licenses/by/4.0/), which permits unrestricted use, distribution, and reproduction in any medium, provided you give appropriate credit to the original author(s) and the source, provide a link to the Creative Commons license, and indicate if changes were made. The Creative Commons Public Domain Dedication waiver (http://creativecommons.org/publicdomain/zero/1.0/) applies to the data made available in this article, unless otherwise stated. 


\section{Background}

Euphorbia lathyris L. is an effective but toxic traditional Chinese medicine (TCM) derived from the family of euphorbiaceae. It can expel water retention with drastic purgative effects, namely, breaking up the static blood and eliminating masses and is often used for the treatment of hydropsy, ascites, anuresis and constipation, amenorrhea, scabies $[1,2]$. It shows several side effects such as irritation and inflammation intense on the skin, mouth and gastrointestinal tract irritation, carcinogenic, and so on. The gastrointestinal mucosa irritation mainly manifested as serious diarrhea. Traditionally, Semen Euphorbiae Pulveratum (SEP), which is another type of Euphorbia lathyris L., is commonly used in TCM practice and is obtained by removing the oil from the seed which is called paozhi. After processing, the toxicity and the capacity of diarrhea was decreased obviously [3]. Interestingly, considerable research efforts have been devoted to the studies on the effect of SEP and SE on diarrhea. Whereas, the intestine protein changes related to intestinal toxicity and the main mechanisms of reducing toxicity by processing of SE remain poorly understood.

With the improvement of two-dimensional polyacrylamide gel electrophoresis (2D-PAGE) and mass spectrometry [4], considerable research efforts have been devoted to the application of proteomics to find possible involved signals in toxic injure induced by some toxins or to determine the modes of action and mechanisms involved in drug- or chemical-induced toxicity $[5,6]$. The isobaric tags for relative and absolute quantitation (iTRAQ) technique is one of the most widely used, innovative and common quantitative proteomics approaches that measure the qualitative and quantitative changes in protein content of a cell or tissue in response to treatment or disease and determine protein-protein and protein-ligand interactions [7]. It can simultaneously analyze 4-8 different specimens, thus increasing throughput while reducing experimental error $[8,9]$. iTRAQ labeling coupled with LC-MS/MS is sensitive, automated, and multidimensional and can detect large molecules (> $20 \mathrm{kDa}$ ) [10]. ITRAQ is suitable for exploratory studies of the processing mechanisms.

In our study, we applied iTRAQ approach to processing for Euphorbia lathyris-induced intestinal toxicity and to identify candidate biomarkers for main mechanisms underlying processing of SE. Bioinformatics analysis including GO analysis, pathway analysis, and network analysis were done to find possible differential pathways. Additionally, the investigation suggested that Euphorbiae factor $1\left(\mathrm{EFL}_{1}\right)$, isolated from Euphorbia lathyris, is the main and active diterpenoids which might mediate diarrhea [11]. We also demonstrated $\mathrm{EFL}_{1}$ group to further compare the DEPs induced by SE and SEP. Finally, western blot analysis was applied further to identify candidate biomarkers, and to confirm and validate significance of the proteomic findings.
These results provided a first insight into scientific connotation of hypothesis that the attenuated of SE after processing expressed lower toxicity from cellular levels in mice model and described an efficient method for mechanisms of toxic TCM processing.

\section{Methods \\ Samples \\ Experimental animals}

KM mice (SPF grade, 18-22 g) were purchased from Sibeifu Co., Ltd. (Beijing, China). All experiments were approved by the Animal Care Committee. Mice were kept at room temperature $\left(23 \pm 1{ }^{\circ} \mathrm{C}\right)$ and $55 \pm 5 \%$ humidity. All experiments were conducted in accordance with the Guiding Principles for the Care and Use of Laboratory Animal, as adopted by the Committee on Animal Research at Beijing University of Chinese Medicine.

\section{Extracts preparations of semen euphorbiae and semen euphorbiae Pulveratum}

Pieces of Euphorbiae Semen (batch number, 1203070692; origin, Jiangxi province, China) were purchased from Anhui Bozhou HuQiao Chinese Herbal Pieces plant. Petroleum ether extract of Semen Euphorbiae, petroleum ether extract of Semen Euphorbiae Pulveratum was provided by Shandong University of Traditional Chinese Medicine. The extraction and isolation methods of Semen Euphorbiae had been published in these articles [12, 13]. Euphorbiae factor 1 was isolated from the petroleum ether extracts of semen Euphorbia by our team [13, 14].

\section{Proteomics extraction procedures Protein preparation}

After $12 \mathrm{~h}$ of fasting, KM mice were randomly divided into 4 groups ( $n=10$ for each group): the group 1 was served as a control, and received only blank $1 \%$ sodium carboxymethyl cellulose solution; meanwhile group 2 was the extracts of SE and group 3 was the extraction of SEP, in which the mice were orally administered at the dose of $1.5 \mathrm{ml} / 20 \mathrm{~g}$ and $1.0 \mathrm{ml} / 20 \mathrm{~g}$, respectively, with the same amount of crude drug. In order to validate the results induced by SE and SEP, group 4 was administered $20 \mathrm{mg} / 20 \mathrm{~g}$ Euphorbiae factor $1\left(\mathrm{EFL}_{1}\right)$ to further verify the protein networks. Mice then received standard diet and water ad libitum. $6 \mathrm{~h}$ later, mice were sacrificed, from which the colon were obtained and frozen in liquid nitrogen immediately until they were used for analysis.

\section{Protein isolation}

The colon tissue samples were ground into powder in liquid nitrogen, extracted with Lysis buffer (7 M urea (Bio-Rad, 161-0731), 2 M Thiourea (Sigma-Aldrich, T7875), 4\% CHAPS (Bio-Rad, 161-0460)) containing complete protease inhibitor Cocktai (Roche, 04693116001). The cell 
was lysed by sonication at $200 \mathrm{~W}$ for 60 s and then extracted $30 \mathrm{~min}$ at room temperature, centrifuged at $4{ }^{\circ} \mathrm{C}$, $15000 \mathrm{~g}$ for $20 \mathrm{~min}$. Before the protein processing, each 5 individual protein samples were mixed equally into 1 specimen. As a result of the strategy, each group contained 2 sample pools, and these sample pools were enrolled to be conducted in subsequent experiments.

\section{Bradford analysis}

Total protein concentration of the samples was determined using a Bradford Assay [15]. Standards of BSA were prepared and all samples and standards were analyzed in duplicate. Protein concentrations and standards of BSA were determined at $595 \mathrm{~nm}$ on an Multiskan MK3 UV-vis spectrophotometer (Thermo, U.S.) with $10 \mu \mathrm{L}$ sample reacted with $300 \mu \mathrm{L}$ Thermo Scientific Pierce Coomassie Plus Bradford Assay (Part No. 23238) 20 min.

\section{Protein reduction, alkylation, and digestion}

Filter-aided sample preparation (FASP) method was used to digest protein based on Jacek $\mathrm{R}$ Wis'niewski et al. [16]. The $200 \mu \mathrm{g}$ calculated protein samples were added to centrifuge tube and $25 \mathrm{mM}$ DTT was added and the samples were incubated at $60{ }^{\circ} \mathrm{C}$ for $1 \mathrm{~h}$. Samples were incubated for $10 \mathrm{~min}$ in the dark after adding $50 \mathrm{mM}$ IAA at room temperature and then centrifuged at $12,000 \mathrm{rpm}$ for $20 \mathrm{~min}$ using Ultrafiltration centrifugal tube(NWCO:10 K). $100 \mu \mathrm{L}$ Dissolution Buffer(iTRAQ ${ }^{\bullet}$ Kit Dissolution Buffer, AB Sciex, USA, PN:4381664) was added to the filter and centrifuged at $12,000 \mathrm{rpm}$ for $20 \mathrm{~min}$. This step was repeated three times. $50 \mu \mathrm{L}$ trypsin, totally $4 \mu \mathrm{g}$, was added and samples were incubated at $37{ }^{\circ} \mathrm{C}$ overnight. After trypsin digestion, samples were centrifuged at 12,000 rpm for $20 \mathrm{~min}$, the digested peptides were collected at the bottom of the tube and mixed with $50 \mu \mathrm{L}$ Dissolution Buffer. Finally $100 \mu \mathrm{L}$ samples were obtained.

\section{ITRAQ labeling}

Each iTRAQ reagent tube (tags-113-121) had $150 \mu \mathrm{l}$ isopropanol added and vortexed thoroughly, then centrifuged. $50 \mu \mathrm{l}$ samples (equal to $100 \mu \mathrm{g}$ digested peptides) were transferred to new tubs and processed according to the manufacturer's protocol for 8-plex iTRAQ reagent (AB Sciex, PN:4390812) by incubation at RT for $2 \mathrm{~h}$ with gentle shaking. The labeled peptide mixtures were then pooled and dried by vacuum centrifugation. Samples were labeled respectively with different isobaric tags as follow: $\mathrm{EFL}_{1}$ samples labeled 113 and 114, control samples labeled 115 and 116, and extraction of SE samples labeled 117 and 118, extraction of SEP samples labeled 119 and 121 . The peptides were labeled with the isobaric tags, incubated at room temperature for $2 \mathrm{~h}$. The labeled peptide mixtures were then pooled and dried by vacuum centrifugation.

\section{iTRAQ-labeled peptide fractionation and proteomic analysis by LC-MS/MS}

The iTRAQ-labeled peptide mixtures were re-suspended in buffer A (2\% ACN, pH 10) and centrifuged at 14,000 g for $20 \mathrm{~min}$. High $\mathrm{pH}$ reversed-phase chromatography was performed to separate the trypsin digestion peptide. The supernatant was loaded onto a $4.6 \times 250 \mathrm{~mm}$ Durashell- $\mathrm{C}_{18}$ containing $5-\mu \mathrm{m}$ particles. The peptides were eluted at a flow rate of $0.7 \mathrm{~mL} / \mathrm{min}$ with a 51-min gradient:0-10 $\mathrm{min}, 5$. 0\% B (Mobile phaseA:2\%ACN,98\% $\mathrm{ddH}_{2} \mathrm{O}, \mathrm{pH}$ 10; Mobile phaseB:98\%ACN,2\%ddH ${ }_{2} \mathrm{O}, \mathrm{pH}$ 10);10-13.4 $\min , 5 \%-8 . \% \mathrm{~B}$; 13.4-31.7 $\min , 8.5 \%-20.5 \% \mathrm{~B} ; 31.7-41 \mathrm{~min}, 20.5 \%-31.0 \% \mathrm{~B}$; 41-46 $\mathrm{min}, 31 \%-90 \% \mathrm{~B} ; 46-47 \mathrm{~min}, 90.0-95.0 \% \mathrm{~B} ; 47-48 \mathrm{~min}$, $95 \%-5 \% \mathrm{~B} ; 48-51 \mathrm{~min}, 5 \% \mathrm{~B}$. The eluted peptides were obtained 40 fractions and finally pooled into 10 fractions through Peak shape.

Then the fraction was re-suspended in $20 \mu \mathrm{L}$ buffer $\mathrm{A}$ (2\% ACN, $0.1 \%$ FA) and centrifuged at $12,000 \mathrm{rpm}$ for $10 \mathrm{~min}$ and $10 \mu \mathrm{L}$ supernatant was loaded onto a $12 \mathrm{~cm} \times$ $75 \mu \mathrm{m}$ EASY-Spray column $\left(\mathrm{C}_{18}, 3 \mu \mathrm{m}\right)$. The samples were loaded at $300 \mathrm{~nL} / \mathrm{min}$ with mobile phase A: $100 \% \mathrm{dd} \mathrm{H}_{2} \mathrm{O} /$ 0.1\% Formic acid; mobile phase B: $100 \%$ ACN/0.1\%FA. The gradient as follows:0-13 $\mathrm{min}, 5-8 \% \mathrm{~B} ; 13-90 \mathrm{~min}, 8030 \% \mathrm{~B}$; 90-100 $\mathrm{min}, 30-50 \% \mathrm{~B} ; 100-105 \mathrm{~min}, 50-95 \% \mathrm{~B} ; 105-115 \mathrm{~min}$, 95\%B;115-116 min,95-5\%B;116-126 min,5\%B.

The peptides were subjected to Nano-electrospray ionization followed by mass spectrometry (MS/MS) using a Q-Exactive mass spectrometer (Thermo Scientific) coupled with an online micro flow HPLC system. Key parameter settings for the Thermo Q-Exactive mass spectrometer were as follows:

spray voltage floating (ISVF) $2.3 \mathrm{KV}$, Capillary Temperature:320 ${ }^{\circ} \mathrm{C}$, Ion source: EASY-Spray source, declustering potential (DP) $100 \mathrm{~V}$.

Full MS:Resolution:70000FWHM;Full Scan AGC target: 3e6;Full Scan Max.IT:20 ms;Scan range:300-1800 m/z; dd-MS2:Resolution:17500 FWHM;AGC target:1e5;Maximum IT:120 ms;Intensity threshold:8.30E + 03;Fragmentation Methods:HCD;NCE:32\%;Top N:20.

\section{Bioinformatics analysis}

Annotations of identified proteins were done with GO for biological processes, molecular functions and cellular component. The analysis were carried out using the Database for Annotation Visualization and Integrated Discovery. Tagged samples were normalized by comparing median protein ratios for the reference channel. Protein quantitative ratios were calculated from the median of all peptide ratios. The proteins with a relative expression of $>1.32$ or $<0.68$, and with a $P$-value $<0.05$ selected as statistically significance to ensure up- and downregulation 


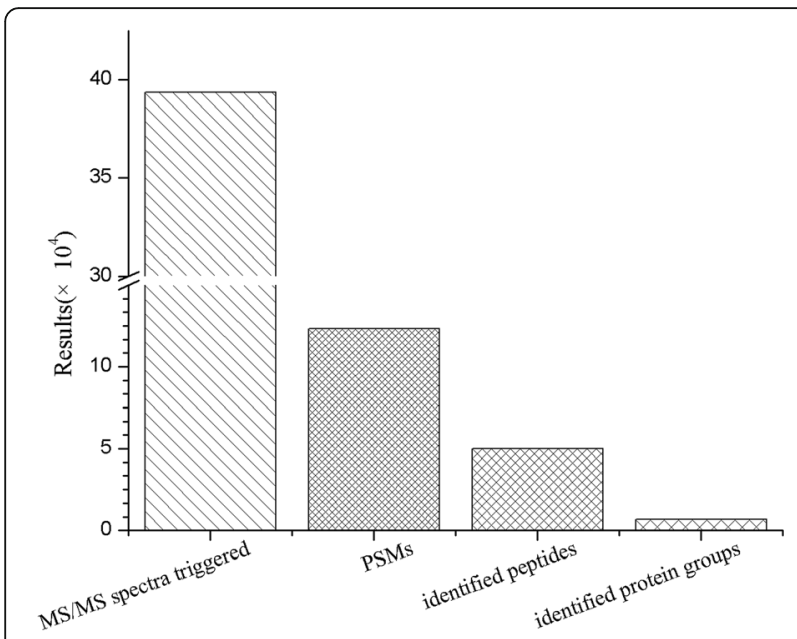

Fig. 1 Basic information statistics of proteome by iTRAQ. MS/MS spectra are the secondary mass spectrums, and PSMs are the secondary mass spectrums after quality control. Protein is identified by Proteome Discoverer 1.4 software

authenticity. The selection parameter was based on the overrepresented GO terms with gene enrichment analysis of $p<0.05$. The protein lists were further analyzed by UniProt database (http://www.uniprot.org/uniprot/?quer$y=$ taxonomy:10090) which gave all canonical pathways, interactions, and network construction with significant enrichment of the input proteins based on data from the UniProt Database, Biocarta, etc. [17]

\section{Western blot analysis}

Western blot analysis were performed to confirm the presence of differentially expressed proteins. Colons from mouse were washed with ice-cold saline and triturated under Liquid Nitrogen. 200 mg powder were lysed in $1.5 \mathrm{ml}$ RIPA buffer and incubated on ice for $60 \mathrm{~min}$, sonicated for $60 \mathrm{~s}$, followed by centrifugation at $12,000 \times \mathrm{g}$ for $15 \mathrm{~min}$ at $4{ }^{\circ} \mathrm{C}$. The total protein concentration was measured using the $\mathrm{BCA}$ protein assay kit (Applygen Technologies Inc. Beijing, China). The supernatant lysates were diluted in $5 \times$ SDS sample buffer and boiled for 5-10 min.

Proteins from individual samples were separated on SDS-PAGE gels and transferred electrophoretically onto PVDF membranes (Millipore, Billerica, MA, USA). The membranes were blocked for $2 \mathrm{~h}$ at room temperature with $3 \%$ non-fat dried milk in Tris-buffered saline (TBST, $20 \mathrm{mM}$ Tris- $\mathrm{HCl}, 137 \mathrm{mM} \mathrm{NaCl}$, and $0.1 \%$ Tween 20, pH 7.6). Then, the membranes were incubated overnight at $4{ }^{\circ} \mathrm{C}$ in a primary antibody against AntiSTAT1 antibody(Abcam, USA), Rabbit Anti-Angiopoietin 4(Beijing Biosynthesis Biotechnology Co., Ltd.,China), Rabbit and Mouse Anti- $\beta$-actin(ZS-Bio. Co., Ltd. Beijing, China). The membranes were then washed with TTBS three times and incubated with horseradish peroxidaseconjugated secondary antibodies (ZS-Bio. Co., Ltd. Beijing, China), Peroxidase-Conjugated Goat anti-Mouse IgG $(\mathrm{H}+\mathrm{L})(\mathrm{ZB}-2305)$ and Peroxidase-Conjugated Goat anti-Rabbit IgG $(\mathrm{H}+\mathrm{L})(\mathrm{ZB}-2301)$.Proteins were detected using an enhanced chemiluminescence (ECL) method (Super ECL plus Detection Reagent, Applygen Technologies Inc.P1010). Protein bands were imaged using a ChemiScope 3300 Mini bio-imaging system (Clinx Science Instruments Co., Ltd. (CSI), Shanghai, China). Bands were normalized with $\beta$ - actin as an internal control. Protein expressions were quantified by chemi analysis and Ang4 and STAT1 were normalized to the beta-actin of each sample. These experiments were each conducted five times.

\section{Results and discussion}

\section{Protein profiling}

MS raw data files were converted into MGF files using Proteome Discoverer 1.4 (PD 1.4, Thermo), and the MGF data files were searched by using the Mascot search engine (Matrix Science, London, UK; version 2.3.02) to identify proteins. Each confident protein identification involves at least one unique peptide. For protein quantification, it was required that a protein contained at least two unique spectra. The quantitative protein ratios were

Table 1 Related information of differentially expressed protein (DEPS) by iTRAQ analysis after intersection

\begin{tabular}{|c|c|c|c|c|c|c|}
\hline Acc no. (NCBI) & Prot names & Gene names & Control & SE & SEP & $\mathrm{EFL}_{1}$ \\
\hline \multicolumn{7}{|c|}{ Down-regulated proteins } \\
\hline Q3TMQ6 & Angiogenin-4 & Ang4 & 1 & 0.5795 & 0.6082 & 0.549 \\
\hline Q62010 & Oviduct-specific glycoprotein & Ovgp1 & 1 & 0.4252 & 0.5825 & 0.451 \\
\hline Q80ZA0 & Intelectin-1b (Intelectin-2) & $|t| n 1 b$ & 1 & 0.4847 & 0.6715 & 0.498 \\
\hline Q8R1M8 & Mucosal pentraxin & Mptx1 & 1 & 0.5352 & 0.5652 & 0.559 \\
\hline V9GXU2 & C2 domain-containing protein 3 & $\mathrm{C} 2 \mathrm{~cd} 3$ & 1 & 0.5372 & 0.636 & 0.463 \\
\hline \multicolumn{7}{|c|}{ Up-regulated proteins } \\
\hline F6R782 & IQ domain-containing protein $\mathrm{E}$ & lqce & 1 & 3.496 & 4.4437 & 4.691 \\
\hline Q9D1X0 & Nucleolar protein 3 (Apoptosis repressor with CARD) & Nol3 Arc & 1 & 1.3665 & 1.5167 & 1.345 \\
\hline
\end{tabular}


Table 2 Summary table showing significantly up-regulated or down-regulated proteins identified by iTRAQ Analysis after combine together

\begin{tabular}{|c|c|c|c|c|c|c|}
\hline Acc no.(NCBI) & Pro names & Gene names & Control & SE & $\mathrm{EFL}_{1}$ & SEP \\
\hline \multicolumn{7}{|l|}{ Up-regulated } \\
\hline Q62010 & Oviduct-specific glycoprotein & Ovgp1 Chit5 Ogp & 1 & 0.4252 & 0.451 & 0.5825 \\
\hline $\mathrm{A} 2 \mathrm{BD} \times 4$ & Potassium voltage-gated channel subfamily G member 1 & Kcng1 & 1 & 0.4347 & 0.856 & 0.6645 \\
\hline P97816 & Protein S100-G & S100 g Calb3 S100d & 1 & 0.4485 & 0.599 & 0.653 \\
\hline Q8BV14 & Ankyrin repeat domain-containing protein 55 & Ankrd55 & 1 & 0.4652 & 0.636 & / \\
\hline Q80ZA0 & Intelectin-1b (Intelectin-2) & $|t| n 1 b|t| n 2|t| n b$ & 1 & 0.4847 & 0.498 & 0.6715 \\
\hline Q8R1M8 & Mucosal pentraxin & Mptx1 Mptx & 1 & 0.5352 & 0.559 & 0.5652 \\
\hline V9GXU2 & C2 domain-containing protein 3 & $\mathrm{C} 2 \mathrm{~cd} 3$ & 1 & 0.5372 & 0.463 & 0.636 \\
\hline P07146 & Anionic trypsin-2 & Prss2 Try2 & 1 & 0.5465 & 0.776 & 0.5967 \\
\hline D6RFD6 & Protein RFT1 homolog & Rft1 & 1 & 0.5687 & 0.771 & 4.6342 \\
\hline Q8VCV1 & Alpha/beta hydrolase domain-containing protein $17 \mathrm{C}$ & Abhd17c & 1 & 0.5707 & 1.271 & 0.7095 \\
\hline Q3TMQ6 & Angiogenin-4 & Ang4 & 1 & 0.5795 & 0.549 & 0.6082 \\
\hline Q08189 & Protein-glutamine gamma-glutamyltransferase $\mathrm{E}$ & Tgm3 Tgase3 & 1 & 0.6085 & 0.728 & 0.528 \\
\hline Q8CIM3 & D-2-hydroxyglutarate dehydrogenase, mitochondrial & D2hgdh & 1 & 0.61 & 0.704 & 1.0195 \\
\hline Q9D7Z6 & Calcium-activated chloride channel regulator 1 & Clca1 & 1 & 0.649 & 0.709 & 0.637 \\
\hline 088273 & Gremlin-2 (Protein related to DAN and cerberus) & Prdc & 1 & 0.6542 & 0.906 & 1.7397 \\
\hline D6RFQ5 & p53 and DNA damage-regulated protein 1 & Pdrg1 & 1 & 0.6585 & 0.683 & 0.6567 \\
\hline Q8BYF6 & Sodium-coupled monocarboxylate transporter 1 & Slc5a8 Smct Smct1 & 1 & 0.6667 & 0.972 & 0.767 \\
\hline H3BLD0 & ATP synthase mitochondrial F1 complex assembly factor 1 & Atpaf1 & 1 & 0.6687 & 0.841 & 0.9637 \\
\hline Q8BXQ3 & Leucine-rich repeat and transmembrane domain-containing protein 1 & Lrtm1 & 1 & 0.6702 & 0.982 & 0.573 \\
\hline A0A075B5L8 & Protein lgkv4-79 & lgkv4-79 & 1 & 0.6722 & 0.688 & 0.8432 \\
\hline Q3V341 & Protein kinase $C$ zeta type & Prkcz & 1 & 0.6775 & 0.606 & 1.052 \\
\hline O88310 & Intelectin-1a & $|t| n 1$ & 1 & 0.6782 & 0.696 & 0.7225 \\
\hline Q9D2X6 & Colon SVA-like protein & Sval1 mcsp mCG_17084 & 1 & 0.6782 & 0.912 & 0.5127 \\
\hline Q64339 & Ubiquitin-like protein ISG15 & Isg15 G1p2 Ucrp & 1 & 0.6887 & 0.922 & 0.6737 \\
\hline Q810Q5 & Normal mucosa of esophagus-specific gene 1 protein & Nmes1 & 1 & 0.693 & 0.832 & 0.5877 \\
\hline P21550 & Beta-enolase & Eno3 Eno-3 & 1 & 0.6965 & 0.876 & 0.6672 \\
\hline P56392 & Cytochrome c oxidase subunit 7A1, mitochondrial & Cox7a1 & 1 & 0.7257 & 0.755 & 0.655 \\
\hline P30275 & Creatine kinase U-type, mitochondrial & Ckmt1 & 1 & 0.7492 & 0.851 & 0.6657 \\
\hline Q6T707 & Protein Scd4 (Stearoyl-CoA desaturase-4) & $\mathrm{Scd} 4$ & 1 & 0.768 & 1.808 & 1.1152 \\
\hline Q9NYQ2 & Hydroxyacid oxidase 2 (HAOX2) & Hao2 Hao3 Haox2 & 1 & 0.771 & 0.721 & 0.658 \\
\hline P09036 & Serine protease inhibitor Kazal-type 3 & Spink3 & 1 & 0.7765 & 0.987 & 0.595 \\
\hline P98086 & Complement $\mathrm{C} 1 \mathrm{q}$ subcomponent subunit $\mathrm{A}$ & Clqa & 1 & 0.785 & 0.406 & 0.8317 \\
\hline F8VPP8 & Protein Zc3h7b & Zc3h7b & 1 & 0.7887 & 0.677 & 0.787 \\
\hline Q5RI75-2 & Ras and EF-hand domain-containing protein homolog & Rasef & 1 & 0.7892 & 0.651 & 0.6965 \\
\hline A2AGQ3 & MAP kinase-activating death domain protein & Madd & 1 & 0.7932 & 1.327 & 1.398 \\
\hline E9QNL5 & Sulfotransferase & Sult1a1 & 1 & 0.796 & 0.659 & 0.7287 \\
\hline P00329 & Alcohol dehydrogenase 1 & Adh1 Adh-1 & 1 & 0.7992 & 1.036 & 0.5625 \\
\hline Q3UZZ6 & Sulfotransferase 1 family member D1 & Sult1d1 St1d1 & 1 & 0.81 & 0.632 & 0.7565 \\
\hline B2RT41 & Protein Zfc $3 \mathrm{~h} 1$ & Zfc3h1 Ccdc131 & 1 & 0.831 & 0.921 & 0.6362 \\
\hline P57774 & Pro-neuropeptide Y [Cleaved into: Neuropeptide $Y$ & Npy & 1 & 0.835 & 1.436 & 1.1532 \\
\hline Q3UW68 & Calpain-13 (Calcium-activated neutral proteinase 13) & Capn13 Gm943 & 1 & 0.838 & 0.987 & 0.669 \\
\hline P13634 & Carbonic anhydrase 1 & Ca1 Car1 & 1 & 0.8425 & 0.622 & 0.818 \\
\hline
\end{tabular}


Table 2 Summary table showing significantly up-regulated or down-regulated proteins identified by iTRAQ Analysis after combine together (Continued)

\begin{tabular}{|c|c|c|c|c|c|c|}
\hline Acc no.(NCBI) & Pro names & Gene names & Control & SE & $\mathrm{EFL}_{1}$ & SEP \\
\hline Q9WUG6 & Insulin-like peptide INSL5 (Insulin-like peptide 5) & Insl5 Rif Rif2 Zins3 & 1 & 0.861 & 1.429 & 0.6775 \\
\hline F7BQ76 & MPN domain-containing protein (Fragment) & Mpnd & 1 & 0.8617 & 0.603 & 1.577 \\
\hline P56393 & Cytochrome c oxidase subunit 7B, mitochondrial & Cox7b & 1 & 0.8755 & 1.075 & 0.6255 \\
\hline Q80WK2 & Organic solute transporter subunit beta & Slc51b Ostb & 1 & 0.881 & 1.373 & 1.177 \\
\hline A2A6K0 & Troponin I, fast skeletal muscle & Tnni2 & 1 & 0.886 & 0.374 & 0.965 \\
\hline Q7TPR4 & Alpha-actinin-1 (Alpha-actinin cytoskeletal isoform) & Actn1 & 1 & 0.888 & 0.857 & 0.6745 \\
\hline G3X940 & Histone acetyltransferase & Kat6a Myst3 & 1 & 0.8887 & 1.618 & 1.1427 \\
\hline P01796 & Ig heavy chain V-III region A4 & 0 & 1 & 0.8935 & 1.481 & 1.0095 \\
\hline G3UWW7 & Protein Zfp40 (Zinc finger protein 40) & Zfp40 mCG_13522 & 1 & 0.9052 & 1.53 & 1.0887 \\
\hline Q9EPS2 & Peptide YY & Pyy & 1 & 0.9135 & 1.349 & 0.974 \\
\hline G3XA21 & MCG134445, isoform CRA_a (Protein Mroh1) & Mroh1 Heatr7a & 1 & 0.922 & 1.114 & 1.3435 \\
\hline Q9Z179 & SHC SH2 domain-binding protein 1 & Shcbp1 Pal & 1 & 0.9295 & 1.107 & 1.4725 \\
\hline 16L974 & TBC1 domain family member 17 & Tbc1d17 & 1 & 0.9315 & 1.155 & 1.3645 \\
\hline P01631 & Ig kappa chain V-II region 26-10 & 0 & 1 & 0.9387 & 1.75 & 0.821 \\
\hline P01878 & Ig alpha chain $C$ region & 0 & 1 & 0.942 & 1.332 & 0.8282 \\
\hline P57776-2 & Elongation factor 1-delta (EF-1-delta) & Eef1d & 1 & 0.9477 & 0.898 & 0.6252 \\
\hline D3Z6J0 & HemK methyltransferase family member 2 , isoform CRA_b & $\begin{array}{l}\text { N6amt1 Hemk2 } \\
\text { mCG_130002 }\end{array}$ & 1 & 0.9562 & 1.524 & 1.4077 \\
\hline Q9WUH1 & Transmembrane protein 115 (Protein PL6 homolog) & Tmem115 Pl6 & 1 & 0.962 & 1.161 & 1.4085 \\
\hline Q8R1U2 & Cell growth regulator with EF hand domain protein 1 & Cgref1 Cgr11 & 1 & 0.9635 & 0.931 & 1.4472 \\
\hline A0A087WNJ2 & Deleted. & 0 & 1 & 0.974 & 0.641 & 0.7125 \\
\hline EOCYMO & Protein 1700019G17Rik & 1700019G17Rik & 1 & 0.9752 & 1.376 & 1.0687 \\
\hline D3Z7B5 & Protein C330027C09Rik & C330027C09Rik & 1 & 0.978 & 1.336 & 1.1042 \\
\hline D3Z652 & Testis-expressed sequence 35 protein & Tex35 & 1 & 0.9797 & 0.993 & 1.3665 \\
\hline F8VQE9 & ANK repeat and $\mathrm{PH}$ domain-containing protein 3 & Agap3 & 1 & 0.9855 & 1.026 & 1.6535 \\
\hline O88665 & Bromodomain-containing protein 7 & Brd7 Bp75 & 1 & 0.9895 & 0.928 & 1.5765 \\
\hline E9Q933 & Transmembrane protein 11 , mitochondrial & Tmem11 & 1 & 0.9942 & 1.5 & 1.1595 \\
\hline \multicolumn{7}{|c|}{ down-regulated } \\
\hline $6 \mathrm{NXH9}$ & Keratin, type II cytoskeletal 73 & Krt73 Kb36 & 1 & 14.265 & 1.559 & 1.4102 \\
\hline F6R782 & IQ domain-containing protein $\mathrm{E}$ & lqce & 1 & 3.496 & 4.691 & 4.4437 \\
\hline A0A075B6A3 & Protein Igha & Igha & 1 & 2.7217 & 1.208 & 1.9125 \\
\hline P00687 & Alpha-amylase 1 & Amy1 & 1 & 2.5575 & 4.341 & 3.1215 \\
\hline Q8C804 & Spindle and centriole-associated protein 1 & Spice1 Ccdc52 & 1 & 2.3742 & 1.928 & 1.8472 \\
\hline O88273 & Formin-2 & Fmn2 & 1 & 2.2107 & 2.234 & 3.8712 \\
\hline D3Z1G3 & Multiple coagulation factor deficiency protein 2 homolog & Mcfd2 & 1 & 2.2085 & 1.694 & 1.931 \\
\hline A2AHB7 & Potassium channel subfamily T member 1 & Kent1 & 1 & 2.181 & 1.35 & 5.51 \\
\hline G3UZX8 & Probable JmjC domain-containing histone demethylation protein $2 \mathrm{C}$ & Jmjd1c & 1 & 2.1745 & 1.124 & 3.0692 \\
\hline P35991 & Tyrosine-protein kinase BTK & Btk Bpk & 1 & 2.1057 & 1.302 & 1.5725 \\
\hline P70213 & Friend virus susceptibility protein 1 & Fv1 & 1 & 1.847 & 1.207 & 1.5947 \\
\hline A0A075B664 & Protein Iglv2 & $\lg \operatorname{lv} 2$ & 1 & 1.8257 & 3.016 & 1.2922 \\
\hline E9Q9F6-2 & Cation channel sperm-associated protein subunit delta & Catsperd Tmem 146 & 1 & 1.7907 & 1.132 & 0.6605 \\
\hline P57791 & CAAX prenyl protease 2 & Rce1 Face2 Rce1a & 1 & 1.6772 & 1.103 & 1.4677 \\
\hline Q9QZU9 & Ubiquitin/ISG15-conjugating enzyme E2 L6 & Ube216 Ubce8 & 1 & 1.648 & 3.026 & 2.0062 \\
\hline A2AF82 & Activator of $90 \mathrm{kDa}$ heat shock protein ATPase homolog 2 & Ahsa2 & 1 & 1.6057 & 1.363 & 1.5 \\
\hline
\end{tabular}


Table 2 Summary table showing significantly up-regulated or down-regulated proteins identified by iTRAQ Analysis after combine together (Continued)

\begin{tabular}{|c|c|c|c|c|c|c|}
\hline Acc no.(NCBI) & Pro names & Gene names & Control & SE & $\mathrm{EFL}_{1}$ & SEP \\
\hline F8VQM0 & Alkaline phosphatase & Akp3 & 1 & 1.6022 & 1.282 & 2.631 \\
\hline P11034 & Mast cell protease 1 & Mcpt1 & 1 & 1.602 & 1.704 & 1.5607 \\
\hline Q6ZWN5 & $40 S$ ribosomal protein 59 & Rps9 & 1 & 1.5622 & 1.053 & 1.3207 \\
\hline Q9DBB8 & Trans-1,2-dihydrobenzene-1,2-diol dehydrogenase & Dhdh & 1 & 1.5585 & 1.268 & 1.6725 \\
\hline Q6NZQ2 & DEAD/H (Asp-Glu-Ala-Asp/His) box polypeptide 31 & Ddx31 & 1 & 1.5305 & 1.169 & 1.3397 \\
\hline G5E8C3 & G protein-coupled receptor, family C, group 5, member A & Gprc5a mCG_22262 & 1 & 1.5077 & 1.168 & 1.4337 \\
\hline Q91WP6 & Serine protease inhibitor $A 3 N$ & Serpina3n Spi2 & 1 & 1.502 & 0.995 & 1.2225 \\
\hline $\mathrm{A} 2 \mathrm{~A} 3 \mathrm{U} 8$ & LON peptidase N-terminal domain and RING finger protein 3 & Lonrf3 & 1 & 1.5017 & 1.274 & 1.9312 \\
\hline P07759 & Serine protease inhibitor A3K & Spi2 & 1 & 1.4825 & 0.804 & 1.2742 \\
\hline Q9DCG2-2 & CD302 antigen & Cd302 Clec13a & 1 & 1.469 & 1.116 & 1.786 \\
\hline P27005 & Protein S100-A8 (Calgranulin-A) & S100a8 Caga Mrp8 & 1 & 1.4637 & 1.522 & 1.154 \\
\hline P04227 & $\mathrm{H}-2$ class II histocompatibility antigen, $\mathrm{A}-\mathrm{Q}$ alpha chain & $\mathrm{H} 2-\mathrm{Aa}$ & 1 & 1.4617 & 1.382 & 0.916 \\
\hline Q8C6B9 & Active regulator of SIRT1 & Rps19bp1 Aros & 1 & 1.4555 & 1.094 & 1.78 \\
\hline P70412 & CUB and zona pellucida-like domain-containing protein 1 & Cuzd1 Itmap1 & 1 & 1.4365 & 1.325 & 1.5315 \\
\hline Q9D083-3 & Kinetochore protein Spc24 & Spc24 Spbc24 & 1 & 1.4297 & 1.978 & 2.0805 \\
\hline P62984 & Ubiquitin-60S ribosomal protein $L 40$ & Uba52 Ubcep2 & 1 & 1.4247 & 1.336 & 1.143 \\
\hline P12804 & Fibroleukin & Fgl2 Fiblp & 1 & 1.4215 & 1.407 & 1.7527 \\
\hline J3QPYO & Protein 1600014C10Rik & 1600014C10Rik & 1 & 1.4165 & 1.485 & 1.8247 \\
\hline B1AXR3 & Perilipin-2 & Plin2 & 1 & 1.414 & 0.975 & 1.3562 \\
\hline Q9ESG9 & $\begin{array}{l}\text { Membrane-associated tyrosine- and threonine-specific cdc2- } \\
\text { inhibitory kinase }\end{array}$ & Pkmyt1 Myt1 & 1 & 1.4137 & 1.332 & 1.9545 \\
\hline P07758 & Alpha-1-antitrypsin 1-1 (AAT) & Serpina1a Dom1 Spi1-1 & 1 & 1.4085 & 0.908 & 1.1527 \\
\hline Q8C7E9 & Cleavage stimulation factor subunit 2 tau variant & Cstf2t Kiaa0689 & 1 & 1.401 & 1.082 & 1.014 \\
\hline F6ZQQ3 & 265 proteasome non-ATPase regulatory subunit 13 & Psmd13 & 1 & 1.3935 & 1.417 & 2.6332 \\
\hline Q91XL1 & Leucine-rich HEV glycoprotein (Protein Lrg1) & Lrg1 Lrg Irhg & 1 & 1.3932 & 0.949 & 1.327 \\
\hline Q03145 & Ephrin type-A receptor 2 & Epha2 Eck Myk2 & 1 & 1.3932 & 1.186 & 1.522 \\
\hline Q9QXA1 & Cysteine and histidine-rich protein 1 & Cyhr1 Chrp & 1 & 1.3902 & 1.191 & 1.0515 \\
\hline Q8BHZ4 & Zinc finger protein 592 (Zfp-592) & Znf592 Kiaa0211 & 1 & 1.3865 & 1.338 & 1.3052 \\
\hline P07724 & Serum albumin & Alb Alb-1 Alb1 & 1 & 1.3842 & 0.816 & 1.2217 \\
\hline V9GX06 & Protein Gm11214 & Gm11214 & 1 & 1.3835 & 1.098 & 1.3607 \\
\hline P29699 & Alpha-2-HS-glycoprotein (Countertrypin) & Ahsg Fetua & 1 & 1.382 & 0.774 & 1.1715 \\
\hline P14148 & $60 S$ ribosomal protein $L 7$ & Rpl7 & 1 & 1.3705 & 0.953 & 1.1725 \\
\hline P42232 & Signal transducer and activator of transcription $5 \mathrm{~B}$ & Stat5b & 1 & 1.3705 & 1.627 & 1.311 \\
\hline P35980 & $60 S$ ribosomal protein L18 & Rpl18 & 1 & 1.3695 & 0.963 & 1.176 \\
\hline Q9D1X0 & Nucleolar protein 3 (Apoptosis repressor with CARD) & Nol3 ArC & 1 & 1.3665 & 1.345 & 1.5167 \\
\hline G3X8Z1 & Calcium-activated chloride channel regulator $4 \mathrm{~A}$ & mCG_119588 & 1 & 1.366 & 1.008 & 1.3725 \\
\hline P01741 & Ig heavy chain $V$ region (Anti-arsonate antibody) & 0 & 1 & 1.3647 & 3.709 & 1.06 \\
\hline A0A087WQ94 & Protein Tns1 & Tns1 & 1 & 1.3562 & 1.117 & 0.9982 \\
\hline A2AACO & Chymotrypsin-C & Ctrc & 1 & 1.354 & 1.062 & 1.3185 \\
\hline E9Q8K5 & Titin & Ttn & 1 & 1.3532 & 0.744 & 1.6037 \\
\hline Q3U3Q1-2 & Serine/threonine-protein kinase ULK3 & Ulk3 & 1 & 1.353 & 1.188 & 1.574 \\
\hline Q91YU8 & Suppressor of SWI4 1 homolog & Ppan Ssf1 & 1 & 1.3522 & 1.167 & 1.1937 \\
\hline Q6LC96 & RXR alpha 2 (RXR alpha 3) & Rxra RXR alpha & 1 & 1.329 & 0.984 & 1.2152 \\
\hline Q3UPV6 & Voltage-gated potassium channel subunit beta- 2 & Kcnab2 & 1 & 1.328 & 1.568 & 1.183 \\
\hline
\end{tabular}


Table 2 Summary table showing significantly up-regulated or down-regulated proteins identified by iTRAQ Analysis after combine together (Continued)

\begin{tabular}{|c|c|c|c|c|c|c|}
\hline Acc no.(NCBI) & Pro names & Gene names & Control & SE & $\mathrm{EFL}_{1}$ & SEP \\
\hline P62301 & $40 S$ ribosomal protein $\mathrm{S} 13$ & Rps13 & 1 & 1.3275 & 1.093 & 1.1617 \\
\hline P22599 & Alpha-1-antitrypsin 1-2 (AAT) (Alpha-1 protease inhibitor 2) & Serpina1b Aat2 & 1 & 1.326 & 0.849 & 1.1235 \\
\hline Q9EP52 & Twisted gastrulation protein homolog 1 & Twsg1 Tsg & 1 & 1.3242 & 1.197 & 0.9917 \\
\hline E9PV04 & Protein Gm8994 & Gm8994 Gm5576 & 1 & 1.3237 & 1.14 & 1.2215 \\
\hline P15119 & Mast cell protease 2 & Mcpt2 & 1 & 1.322 & 1.36 & 1.0482 \\
\hline Q3ZAR9 & Nr2c2 protein (Nuclear receptor subfamily 2 group C member 2) & $\mathrm{Nr} 2 \mathrm{c} 2$ & 1 & 1.3202 & 1.395 & 1.158 \\
\hline Q8BSI6 & $\mathrm{R} 3 \mathrm{H}$ and coiled-coil domain-containing protein 1 & R3hcc1 & 1 & 1.319 & 1.279 & 1.569 \\
\hline Q32M21-2 & Gasdermin-A2 & Gsdma2 Gsdm2 & 1 & 1.3125 & 1.482 & 1.233 \\
\hline Q80TL0 & Protein phosphatase $1 \mathrm{E}$ & Ppm1e Camkn & 1 & 1.3082 & 0.645 & 1.1805 \\
\hline F6RUC3 & Ribonucleoside-diphosphate reductase subunit M2 (Fragment) & Rrm2 & 1 & 1.3075 & 1.238 & 1.4467 \\
\hline A2ALH2 & Putative tRNA & Ftsj1 & 1 & 1.296 & 1.3 & 1.5377 \\
\hline Q8BGSO-2 & Protein MAK16 homolog (Protein RBM13) & Mak16 Rbm13 & 1 & 1.2927 & 1.195 & 1.334 \\
\hline Q8BHY2 & Nucleolar complex protein 4 homolog (NOC4 protein homolog) & Noc4l & 1 & 1.2877 & 1.455 & 1.5922 \\
\hline Q99J23 & GH3 domain-containing protein & Ghdc D11lgp1e & 1 & 1.287 & 1.231 & 1.3732 \\
\hline O35640 & Annexin A8 & Anxa8 Anx8 & 1 & 1.277 & 1.55 & 1.1167 \\
\hline Q60590 & Alpha-1-acid glycoprotein 1 & Orm1 Agp1 Orm-1 & 1 & 1.263 & 1.116 & 1.4175 \\
\hline P35461 & Lymphocyte antigen 6G (Ly-6G) & Ly6g & 1 & 1.2495 & 0.915 & 1.331 \\
\hline P42225 & Signal transducer and activator of transcription 1 & Stat1 & 1 & 1.2437 & 1.533 & 0.9722 \\
\hline Q8VEJ4 & Notchless protein homolog 1 & Nle1 & 1 & 1.2432 & 1.251 & 1.3997 \\
\hline F6S522 & Claspin & Clspn & 1 & 1.2415 & 1.134 & 7.6765 \\
\hline Q8BHN5 & RNA-binding protein 45 & Rbm45 Drb1 Drbp1 & 1 & 1.2387 & 1.232 & 1.4235 \\
\hline P31725 & Protein S100-A9 & S100a9 & 1 & 1.2345 & 1.351 & 1.028 \\
\hline F8WJ43 & Merlin & $\mathrm{Nf2}$ & 1 & 1.234 & 1.168 & 1.441 \\
\hline Q8C3X8 & Lipase maturation factor 2 & $\begin{array}{l}\text { Lmf2 Tmem112b } \\
\text { Tmem153 }\end{array}$ & 1 & 1.2307 & 0.928 & 1.5145 \\
\hline E9Q8D0 & Protein Dnajc21 & Dnajc21 & 1 & 1.227 & 1.476 & 1.1372 \\
\hline Q9QXA1-2 & Cysteine and histidine-rich protein 1 & Cyhr1 Chrp & 1 & 1.2205 & 1.374 & 1.054 \\
\hline Q3UW98 & Chloride channel calcium activated 7 & Clca4b Al747448 & 1 & 1.2187 & 1.401 & 1.0597 \\
\hline A0A075B5M8 & Protein Igkv12-38 & $\operatorname{lgkv12-38}$ & 1 & 1.218 & 1.337 & 1.2272 \\
\hline Q4QRL3 & Coiled-coil domain-containing protein 88B & Ccdc88b Ccdc88 & 1 & 1.2172 & 1.485 & 1.392 \\
\hline Q3TBT3-3 & Stimulator of interferon genes protein (mSTING) & Tmem173 Eris Mita & 1 & 1.2167 & 1.441 & 1.1297 \\
\hline P08905 & $\begin{array}{l}\text { Lysozyme C-2 (EC 3.2.1.17) (1,4-beta-N-acetylmuramidase C) } \\
\text { (Lysozyme C type M) }\end{array}$ & Lyz2 Lyz Lyzs & 1 & 1.2162 & 1.353 & 1.0305 \\
\hline Q9DCS1 & $\begin{array}{l}\text { Transmembrane protein } 176 \mathrm{~A} \text { (Gene signature 188) } \\
\text { (Kidney-expressed gene } 2 \text { protein) }\end{array}$ & Tmem176a Gs188 Keg2 & 1 & 1.2157 & 1.248 & 1.5587 \\
\hline P84228 & Histone H3.2 & Hist1h3b & 1 & 1.214 & 0.511 & 1.0842 \\
\hline D3Z408 & High affinity cGMP-specific 3',5'-cyclic phosphodiesterase 9A & Pde9a & 1 & 1.2137 & 1.307 & 1.3392 \\
\hline E9Q4G7 & Casein kinase I isoform alpha & Csnk1a1 & 1 & 1.2105 & 1.47 & 1.643 \\
\hline P05533 & $\begin{array}{l}\text { Lymphocyte antigen 6A-2/6E-1 (Ly-6A.2/Ly-6E.1) (Stem cell antigen 1) } \\
\text { (SCA-1) (T-cell-activating protein) (TAP) }\end{array}$ & Ly6a Ly6 & 1 & 1.2085 & 1.378 & 1.1695 \\
\hline P01844 & Ig lambda-2 chain $\mathrm{C}$ region & lglc2 & 1 & 1.2072 & 2.441 & 1.087 \\
\hline G3X8S8 & MCG14499 (tRNA-splicing endonuclease subunit Sen15) & Tsen15 mCG_14499 & 1 & 1.2065 & 1.143 & 1.4907 \\
\hline F6QQ13 & Selenocysteine insertion sequence-binding protein 2-like (Fragment) & Secisbp21 & 1 & 1.2035 & 1.149 & 1.3285 \\
\hline P58501 & PAX3- and PAX7-binding protein 1 (PAX3/7BP) (GC-rich sequence & Paxbp1 Gcfc Gcfc1 & 1 & 1.2035 & 1.488 & 1.2637 \\
\hline
\end{tabular}
DNA-binding factor 1) 
Table 2 Summary table showing significantly up-regulated or down-regulated proteins identified by iTRAQ Analysis after combine together (Continued)

\begin{tabular}{|c|c|c|c|c|c|c|}
\hline Acc no.(NCBI) & Pro names & Gene names & Control & SE & $\mathrm{EFL}_{1}$ & SEP \\
\hline Q9JLM9 & Growth factor receptor-bound protein 14 (GRB14 adapter protein) & Grb14 & 1 & 1.1975 & 0.601 & 1.1215 \\
\hline P59328-2 & $\begin{array}{l}\text { WD repeat and HMG-box DNA-binding protein } 1 \text { (Acidic nucleoplasmic } \\
\text { DNA-binding protein 1) (And-1) }\end{array}$ & Wdhd1 And1 & 1 & 1.1922 & 1.221 & 1.4022 \\
\hline A2A5Z6-2 & $\begin{array}{l}\text { E3 ubiquitin-protein ligase SMURF2 (EC 6.3.2.-) (SMAD ubiquitination } \\
\text { regulatory factor 2) (SMAD-specific E3 ubiquitin-protein ligase 2) }\end{array}$ & Smurf2 & 1 & 1.1902 & 1.098 & 1.3955 \\
\hline Q8CIA9 & Hippocampus abundant transcript-like protein 1 & Hiatl1 & 1 & 1.1852 & 1.098 & 1.3277 \\
\hline H3ВKB9 & Protein zwilch homolog (Fragment) & Zwilch & 1 & 1.1817 & 1.114 & 1.3972 \\
\hline Q5SUA5 & Unconventional myosin-lg & Myo1g & 1 & 1.1747 & 1.196 & 1.3717 \\
\hline P03991 & $\mathrm{H}-2$ class I histocompatibility antigen, $\mathrm{K}-\mathrm{W} 28$ alpha chain & $\mathrm{H} 2-\mathrm{K} 1 \mathrm{H} 2-\mathrm{K}$ & 1 & 1.1682 & 1.554 & 0.966 \\
\hline Q61542 & $\begin{array}{l}\text { StAR-related lipid transfer protein } 3 \text { (Protein ES 64) (Protein MLN 64) } \\
\text { (START domain-containing protein 3) (StARD3) }\end{array}$ & Stard3 Es64 Mln64 & 1 & 1.1672 & 1.663 & 1.496 \\
\hline A8C756 & Thyroid adenoma-associated protein homolog & Thada Kiaa1767 & 1 & 1.165 & 1.299 & 1.382 \\
\hline Q80ZI6 & $\begin{array}{l}\text { E3 ubiquitin-protein ligase LRSAM1 (EC 6.3.2.-) (Leucine-rich repeat and } \\
\text { sterile alpha motif-containing protein 1) (Tsg101-associated ligase) }\end{array}$ & Lrsam1 & 1 & 1.1627 & 1.094 & 1.59 \\
\hline F6RR81 & Protein cordon-bleu (Fragment) & Cobl & 1 & 1.1585 & 1.355 & 1.1932 \\
\hline Q8R2S8 & CD177 antigen (CD antigen CD177) & Cd177 & 1 & 1.158 & 1.426 & 1.0102 \\
\hline A2ALA0 & Surfeit locus protein 6 & Surf6 & 1 & 1.1567 & 1.218 & 1.3962 \\
\hline Q5SUW0 & Growth factor receptor-bound protein 10 (Fragment) & Grb10 & 1 & 1.1552 & 1.019 & 1.3747 \\
\hline Q9CQS2 & $\begin{array}{l}\text { H/ACA ribonucleoprotein complex subunit } 3 \text { (Nucleolar protein 10) } \\
\text { (Nucleolar protein family A member 3) (snoRNP protein NOP10) }\end{array}$ & Nop10 Nola3 & 1 & 1.1455 & 1.37 & 1.1737 \\
\hline D3YUW8 & Pogo transposable element with ZNF domain & Pogz & 1 & 1.1365 & 1.373 & 1.3605 \\
\hline Q62293 & Interferon-gamma-inducible GTPase Ifggb5 protein & Tgtp & 1 & 1.1357 & 1.958 & 1.0067 \\
\hline Q8BX57-3 & $\begin{array}{l}\text { PX domain-containing protein kinase-like protein (Modulator of } \\
\text { Na,K-ATPase) (MONaKA) }\end{array}$ & Pxk & 1 & 1.1355 & 0.867 & 1.3607 \\
\hline EOCYU9 & Sjoegren syndrome/scleroderma autoantigen 1 homolog & Sssca1 & 1 & 1.135 & 1.705 & 1.5802 \\
\hline Q9R0X0-3 & $\begin{array}{l}\text { Mediator of RNA polymerase II transcription subunit } 20 \text { (Mediator } \\
\text { complex subunit 20) (TRF-proximal protein homolog) }\end{array}$ & Med20 Trfp & 1 & 1.1335 & 1.088 & 1.3255 \\
\hline P18527 & Ig heavy chain $\vee$ region 914 & 0 & 1 & 1.133 & 1.071 & 0.618 \\
\hline $\mathrm{A} 2 \mathrm{~A} 6 \mathrm{~A} 1$ & G patch domain-containing protein 8 & Gpatch8 Gpatc8 Kiaa0553 & 1 & 1.1295 & 1.861 & 1.0447 \\
\hline 035242 & $\begin{array}{l}\text { Protein FAN (Factor associated with neutral sphingomyelinase activation) } \\
\text { (Factor associated with N-SMase activation) }\end{array}$ & Nsmaf Fan & 1 & 1.1275 & 1.116 & 1.417 \\
\hline P04184 & Thymidine kinase, cytosolic (EC 2.7.1.21) & Tk1 Tk-1 & 1 & 1.1222 & 1.288 & 1.638 \\
\hline Q80VC9-2 & Calmodulin-regulated spectrin-associated protein 3 (Protein Nezha) & Camsap3 Kiaa1543 & 1 & 1.1107 & 1.308 & 1.492 \\
\hline S4R2KO & Protein Pdf & Pdf & 1 & 1.1082 & 1.644 & 1.4732 \\
\hline Q8BZR9 & Uncharacterized protein C17orf85 homolog & 0 & 1 & 1.108 & 1.132 & 1.6712 \\
\hline Q8K4Q0-5 & $\begin{array}{l}\text { Regulatory-associated protein of mTOR (Raptor) (p150 target of } \\
\text { rapamycin (TOR)-scaffold protein) }\end{array}$ & Rptor Raptor & 1 & 1.105 & 1.153 & 1.4442 \\
\hline Q6P9L6 & Kinesin-like protein KIF15 (Kinesin-like protein 2) (Kinesin-like protein 7) & Kif15 Klp2 Knsl7 & 1 & 1.1012 & 1.367 & 1.3967 \\
\hline Q9CR76 & Transmembrane protein 186 & Tmem186 & 1 & 1.0997 & 0.655 & 1.0117 \\
\hline Q924Z6-2 & Exportin-6 (Exp6) (Ran-binding protein 20) & Xpo6 Ranbp20 & 1 & 1.0997 & 1.209 & 1.5217 \\
\hline Q8BZT5 & Leucine-rich repeat-containing protein 19 & Lrrc19 & 1 & 1.0952 & 1.379 & 1.2207 \\
\hline P11247 & $\begin{array}{l}\text { Myeloperoxidase (MPO) (EC 1.11.2.2) [Cleaved into: Myeloperoxidase } \\
\text { light chain; Myeloperoxidase heavy chain] }\end{array}$ & Mpo & 1 & 1.0945 & 1.195 & 1.415 \\
\hline A8DUK4 & Beta-globin (Protein Hbb-bs) (Protein Hbb-bt) & $\begin{array}{l}\text { Hbbt1 Hbb-bs Hbb-bt } \\
\text { Hbbt2 }\end{array}$ & 1 & 1.0942 & 2.14 & 0.8445 \\
\hline P01630 & Ig kappa chain V-II region 7S34.1 & 0 & 1 & 1.094 & 1.405 & 1.2252 \\
\hline Q8CGN5 & Perilipin-1 (Lipid droplet-associated protein) (Perilipin A) & Plin1 Peri Plin & 1 & 1.0895 & 0.885 & 1.3687 \\
\hline
\end{tabular}


Table 2 Summary table showing significantly up-regulated or down-regulated proteins identified by iTRAQ Analysis after combine together (Continued)

\begin{tabular}{|c|c|c|c|c|c|c|}
\hline Acc no.(NCBI) & Pro names & Gene names & Control & SE & $\mathrm{EFL}_{1}$ & SEP \\
\hline Q9CQT2 & RNA-binding protein 7 (RNA-binding motif protein 7) & Rbm7 & 1 & 1.0877 & 1.142 & 1.333 \\
\hline F7BJK1 & Protein Pcdh1 (Fragment) & Pcdh1 & 1 & 1.0875 & 0.927 & 1.8367 \\
\hline Q80TA6-2 & Myotubularin-related protein 12 & Mtmr12 Kiaa1682 & 1 & 1.0835 & 1.091 & 1.5237 \\
\hline P54754 & $\begin{array}{l}\text { Ephrin type-B receptor } 3 \text { (EC 2.7.10.1) (Developmental kinase 5) } \\
\text { (mDK-5) (Tyrosine-protein kinase receptor SEK-4) }\end{array}$ & Ephb3 Etk2 Mdk5 Sek4 & 1 & 1.082 & 1.341 & 1.1597 \\
\hline D3Z769 & Protein lin-37 homolog (Fragment) & $\operatorname{Lin} 37$ & 1 & 1.0795 & 1.116 & 1.5232 \\
\hline A0A075B5X9 & Ig heavy chain $V$ region B1-8/186-2 (Fragment) & lghv1-72 & 1 & 1.0795 & 1.415 & 1.2 \\
\hline F6TLBO & DNA-directed RNA polymerase, mitochondrial (Fragment) & Polrmt & 1 & 1.077 & 1.111 & 1.3495 \\
\hline A0A087WRI5 & Adenylate kinase isoenzyme 6 & Ak6 & 1 & 1.075 & 1.346 & 1.1457 \\
\hline Q8BK35 & MCG2065, isoform CRA_c (PreS1 binding protein) (Protein Gltscr2) & Gltscr2 mCG_2065 & 1 & 1.074 & 0.953 & 1.557 \\
\hline Q9CQT0 & $\begin{array}{l}\text { tRNA(His) guanylyltransferase (EC 2.7.7.79) } \\
\text { (tRNA-histidine guanylyltransferase) }\end{array}$ & Thg11 mCG_22296 & 1 & 1.0722 & 1.14 & 1.4462 \\
\hline A0A075B677 & Protein Igkv4-53 & lgkv4-53 & 1 & 1.0705 & 1.361 & 0.986 \\
\hline G3UWZ0 & Bromodomain adjacent to zinc finger domain protein $1 \mathrm{~A}$ & Bazla & 1 & 1.0702 & 1.564 & 1.3232 \\
\hline F6R2G3 & Mucin-4 (Fragment) & Muc4 & 1 & 1.0695 & 1.286 & 1.3432 \\
\hline Q6GU68 & Immunoglobulin superfamily containing leucine-rich repeat protein & $|s| r$ & 1 & 1.068 & 1.154 & 1.3577 \\
\hline E9PWH6 & HEAT repeat-containing protein 3 & Heatr3 & 1 & 1.0605 & 1.102 & 1.4625 \\
\hline Q8BLH7 & HIRA-interacting protein 3 & Hirip3 & 1 & 1.0587 & 1.496 & 1.4912 \\
\hline Q62264 & $\begin{array}{l}\text { Thyroid hormone-inducible hepatic protein (Spot } 14 \text { protein) } \\
\text { (S14) (SPOT14) }\end{array}$ & Thrsp S14 & 1 & 1.0582 & 0.943 & 1.4015 \\
\hline Q99M73 & $\begin{array}{l}\text { Keratin, type II cuticular Hb4 (65 kDa type II keratin) (Keratin-84) } \\
\text { (K84) (Type II hair keratin Hb4) (Type-II keratin Kb24) }\end{array}$ & Krt84 Krt2-16 Krthb4 & 1 & 1.0557 & 1.17 & 1.3252 \\
\hline Q9D856 & $\begin{array}{l}\text { Zinc transporter ZIP5 (Solute carrier family } 39 \text { member 5) (Zrt- and } \\
\text { Irt-like protein 5) (ZIP-5) }\end{array}$ & Slc39a5 Zip5 & 1 & 1.0555 & 1.484 & 1.4005 \\
\hline F7BJB9 & Protein Morc3 & Morc3 & 1 & 1.0525 & 1.375 & 1.2087 \\
\hline B7ZWM8 & $\begin{array}{l}\text { Leucine-rich repeat and calponin homology domain-containing } \\
\text { protein } 3 \text { (Lrch3 protein) }\end{array}$ & Lrch3 & 1 & 1.0505 & 1.128 & 1.3452 \\
\hline D3Z6K8 & Ras-specific guanine nucleotide-releasing factor 2 & Rasgrf2 & 1 & 1.0482 & 1.047 & 1.3875 \\
\hline Q5FWI3 & Transmembrane protein 2 & Tmem2 Kiaa1412 & 1 & 1.0462 & 1.163 & 1.4667 \\
\hline G3UZL2 & RCC1 and BTB domain-containing protein 1 (Fragment) & Rcbtb1 & 1 & 1.0417 & 1.433 & 1.2967 \\
\hline Q61666-4 & Protein HIRA (TUP1-like enhancer of split protein 1) & Hira Tuple1 & 1 & 1.0405 & 1.127 & 1.3862 \\
\hline P53569 & $\begin{array}{l}\text { CCAAT/enhancer-binding protein zeta (CCAAT-box-binding } \\
\text { transcription factor) (CBF) (CCAAT-binding factor) }\end{array}$ & Cebpz Cbf2 Cebpa-rs1 & 1 & 1.0367 & 1.325 & 1.7395 \\
\hline Q9JJF3 & $\begin{array}{l}\text { Bifunctional lysine-specific demethylase and histidyl-hydroxylase NO66 } \\
\text { (EC 1.14.11.-) (EC 1.14.11.27) (Histone lysine demethylase NO66) }\end{array}$ & No66 Mapjd MNCb-7109 & 1 & 1.0337 & 1.68 & 1.1642 \\
\hline Q9DAA6 & Exosome complex component CSL4 (Exosome component 1) & Exosc1 Cs/4 & 1 & 1.033 & 1.326 & 1.2455 \\
\hline A0A087WQR9 & NEDD8-conjugating enzyme UBE2F (Fragment) & Ube2f & 1 & 1.0292 & 1.352 & 1.2977 \\
\hline Q970E6 & $\begin{array}{l}\text { Interferon-induced guanylate-binding protein } 2 \text { (GTP-binding protein 2) } \\
\text { (GBP-2) (mGBP-2) (mGBP2) (Guanine nucleotide-binding protein 2) }\end{array}$ & Gbp2 & 1 & 1.0292 & 1.432 & 0.9467 \\
\hline B7ZMP1-2 & $\begin{array}{l}\text { Probable Xaa-Pro aminopeptidase } 3 \text { (X-Pro aminopeptidase 3) } \\
\text { (EC 3.4.11.9) (Aminopeptidase P3) (APP3) }\end{array}$ & Xpnpep3 & 1 & 1.0285 & 0.927 & 1.4122 \\
\hline D3YWR2 & B-cell linker protein & Blnk & 1 & 1.0237 & 1.595 & 1.1195 \\
\hline H7BX32 & Nuclear envelope pore membrane protein POM 121 & Pom121 & 1 & 1.0165 & 1.187 & 1.3717 \\
\hline Q99N87 & $28 \mathrm{~S}$ ribosomal protein $\mathrm{S} 5$, mitochondrial (MRP-S5) (S5mt) & Mrps5 & 1 & 1.0147 & 1.41 & 0.9545 \\
\hline Q8CBC4 & Consortin & Cnst & 1 & 1.0092 & 1.33 & 1.19 \\
\hline A2AER8 & Polyglutamine-binding protein 1 & Pqbp1 & 1 & 1.0077 & 1.477 & 0.9262 \\
\hline A8Y5N4 & 17-beta-hydroxysteroid dehydrogenase 13 & Hsd17b13 & 1 & 1.006 & 0.603 & 0.7325 \\
\hline
\end{tabular}


Table 2 Summary table showing significantly up-regulated or down-regulated proteins identified by iTRAQ Analysis after combine together (Continued)

\begin{tabular}{|c|c|c|c|c|c|c|}
\hline Acc no.(NCBI) & Pro names & Gene names & Control & SE & $\mathrm{EFL}_{1}$ & SEP \\
\hline Q9D811 & Marginal zone B- and B1-cell-specific protein & Mzb1 Pacap & 1 & 1.006 & 1.348 & 0.9347 \\
\hline P26618 & Platelet-derived growth factor receptor alpha & Pdgfra & 1 & 1.0032 & 1.152 & 1.4392 \\
\hline P55088-2 & Aquaporin-4 (AQP-4) & Aqp4 & 1 & 1.0005 & 1.327 & 0.8442 \\
\hline
\end{tabular}

Acc no Accession number, Prot name Protein name, SE Semen Euphorbiae, SEP Semen Euphorbiae Pulveratum, EFL ${ }_{1}$ Euphorbiae Factor 1

weighted and normalized by the median ratio in Mascot. As shown in Fig. 1, a total of 393,357 MS/MS spectra which are the secondary mass spectrums were identified by iTRAQ-coupled 2D LC-MS/MS analysis in mice intestine tissues. Among them, 123,136 peptide spectrummatch (PSM) were found. In addition, the LC-MS/MS analysis employed here resulted in identification of 50,007 total peptides with 6727 identified protein groups.

\section{Identification of differentially expressed proteins using iTRAQ labeling and LC-MS/MS}

Through analysis with software, data were processed using the Proteome Discoverer Software 4.0 utilizing the Mascot (Matrix Science,London, U.K.; version 2.3.0) Algorithm. In this algorithm, Parameters set for the searching were iTRAQ eight plex peptide-labeled, trypsin digestion with only two maximum miss cleavage, carboxymate for cysteine residue and oxidation for methionine. The tolerances were specified as $\pm 15 \mathrm{ppm}$ for peptides and $\pm 20 \mathrm{mmu}$ for MS/MS fragments. The mice protein database was downloaded from UniProt. The false discovery rate (FDR) was controlled at the $1 \%$ level. Distributional normality and homogeneity of variance were tested for numerical data. Values were given as mean \pm SD. To reduce probability of false peptide identification, only peptides with a fold change cut-off ratio of $>1.32$ or $<0.68$ and ones with $p$-values smaller than 0.05 in the analysis (where $P$-value $<0.05$ indicates $>95 \%$ confidence of a change
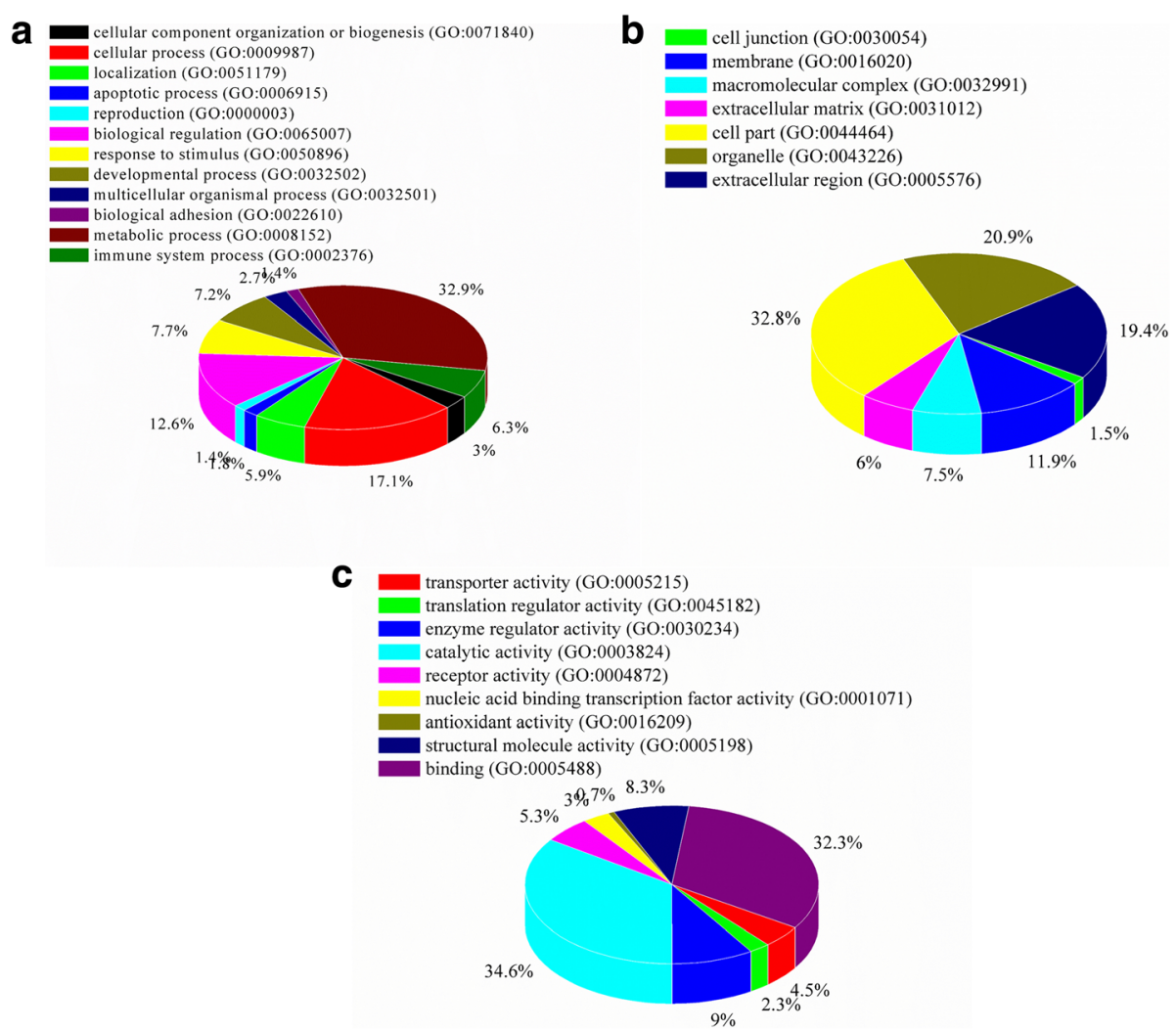

Fig. 2 Bioinformatics analysis of the differentially expressed proteins (ratio $\geq 1.32$ or $\leq 0.68$ fold). a Biological process (b) Cellular component; (c). Molecular function 
in protein concentration irrespective of the magnitude of the change) was selected to designate differentially expressed proteins. The similar experimental design was described in previous study [18-20]. Among them, proteins that displayed significantly altered expression levels comparing with the control group were considered as upregulated or down-regulated differentially expressed proteins (DEPs), respectively. With this filter, we identified 103 DEPs in $\mathrm{EFL}_{1}$ group, including 82 up-regulated proteins and 21 down-regulated proteins. Besides, regarding to $70 \mathrm{DEPs}$ from SE-treated group compared to control group, 47 proteins were up-regulated, and 23 proteins were down-regulated. Moreover, there were 96 upregulated proteins and 26 down-regulated proteins, totaling 122 proteins in the SEP-treated groups were identified relative to control. Further analysis indicated that the three test groups shared 7 DEPs in the colon tissues of mice after intersection, of which, 5 proteins were downregulated and 2 proteins up-regulated (Table 1). Meanwhile, there were 295 differentially expressed proteins in the colon tissues of mice in union of DEPs of SE and SEP, $\mathrm{EFL}_{1}$, of which, 70 proteins were down-regulated and 225 proteins up-regulated (Table 2). These proteins were subjected to gene-ontology enrichment.

\section{GO ontology analysis}

To elucidate the biological significance of these differentially modified proteins, we performed GO analysis and

Table 3 Pathway Enrichment analysis of differentially expressed proteins relative to SE compared with control group

\begin{tabular}{lll}
\hline NO & Maps & pValue \\
\hline 1 & $\begin{array}{l}\text { Immune response_Oncostatin M signaling via } \\
\text { JAK-Stat in mouse cells }\end{array}$ & 0.000195 \\
2 & $\begin{array}{l}\text { Immune response_Oncostatin M signaling via } \\
\text { JAK-Stat in human cells }\end{array}$ & 0.000242 \\
3 & $\begin{array}{l}\text { Development_Thrombopoetin signaling via } \\
\text { JAK-STAT pathway }\end{array}$ & 0.000294 \\
4 & Immune response_IL-15 signaling via JAK-STAT cascade & 0.000322 \\
5 & Development_Transcription factors in segregation & 0.000552 \\
& of hepatocytic lineage & \\
6 & Immune response_IL-7 signaling in T lymphocytes & 0.000887 \\
7 & Immune response_IL-7 signaling in B lymphocytes & 0.001136 \\
8 & Cell adhesion_Ephrin signaling \\
9 & Neurophysiological process_Receptor-mediated & 0.001244 \\
& axon growth repulsion & 0.001244 \\
10 & Immune response_IL-5 signaling \\
11 & Signal transduction_PTMs in IL-12 signaling pathway & 0.001415 \\
12 & G-protein signaling_Rap1B regulation pathway & 0.013047 \\
13 & Protein folding_Membrane trafficking and signal & 0.022438 \\
& transduction of G-alpha (i) heterotrimeric G-protein & \\
14 & Immune response_IL-12 signaling pathway & 0.027103 \\
15 & Development_Glucocorticoid receptor signaling & 0.028266 \\
\hline
\end{tabular}

Table 4 Pathway Enrichment analysis of differentially expressed proteins relative to SEP compared with control group

\begin{tabular}{lll}
\hline NO & Maps & pValue \\
\hline 1 & $\begin{array}{l}\text { Cytoskeleton remodeling_Role of PDGFs in cell } \\
\text { migration }\end{array}$ & 0.002188 \\
2 & Glycolysis and gluconeogenesis p.3 / Human version & 0.002188 \\
3 & Glycolysis and gluconeogenesis p.3 & 0.002188 \\
4 & Development_PDGF signaling via STATs and NF-kB & 0.003877 \\
5 & Normal and pathological TGF-beta-mediated regulation & 0.004119 \\
& of cell proliferation & \\
6 & Cell adhesion_Ephrin signaling & 0.007559 \\
7 & Neurophysiological process_Receptor-mediated axon & 0.007559 \\
& growth repulsion & 0.008224 \\
8 & Development_PDGF signaling via MAPK cascades & 0.009631 \\
9 & Some pathways of EMT in cancer cells & 0.011137 \\
10 & Aberrant B-Raf signaling in melanoma progression & 0.014439 \\
11 & Transport_Macropinocytosis regulation by growth factors & 0.015773 \\
12 & Glycolysis and gluconeogenesis (short map) & 0.031748 \\
13 & G-protein signaling_Rap1B regulation pathway & 0.034254 \\
14 & Cell adhesion_Chemokines and adhesion & 0.035519 \\
15 & Cytoskeleton remodeling_Cytoskeleton remodeling & \\
\hline & &
\end{tabular}

Table 5 Pathway Enrichment analysis of differentially expressed proteins relative to $\mathrm{EFL}_{1}$ compared with control

NO. Maps pValue

1 Development_Angiopoietin - Tie2 signaling 0.000027

2 Immune response_LL-7 signaling in T lymphocytes $\quad 0.000035$

3 Immune response_L-7 signaling in B lymphocytes $\quad 0.000051$

4 Immune response_Antiviral actions of Interferons 0.000090

5 Immune response_Oncostatin M signaling via JAK-Stat $\quad 0.000425$ in mouse cells

6 Immune response_Oncostatin M signaling via JAK-Stat $\quad 0.000526$ in human cells

7 Development_Thrombopoetin signaling via JAK-STAT 0.000639 pathway

8 Immune response_IL-15 signaling via JAK-STAT cascade 0.000699

9 Immune response_IL-23 signaling pathway 0.000827

10 Signal transduction_PTMs in IL-23 signaling pathway 0.001274

11 Development_PDGF signaling via STATs and NF-kB 0.001357

12 Immune response_IL-22 signaling pathway 0.001532

13 Development_EPO-induced Jak-STAT pathway 0.001623

14 Development_Growth hormone signaling via STATs and 0.001623 $\mathrm{PLC/IP3}$

15 Immune response_LL-9 signaling pathway $\quad 0.001717$ 


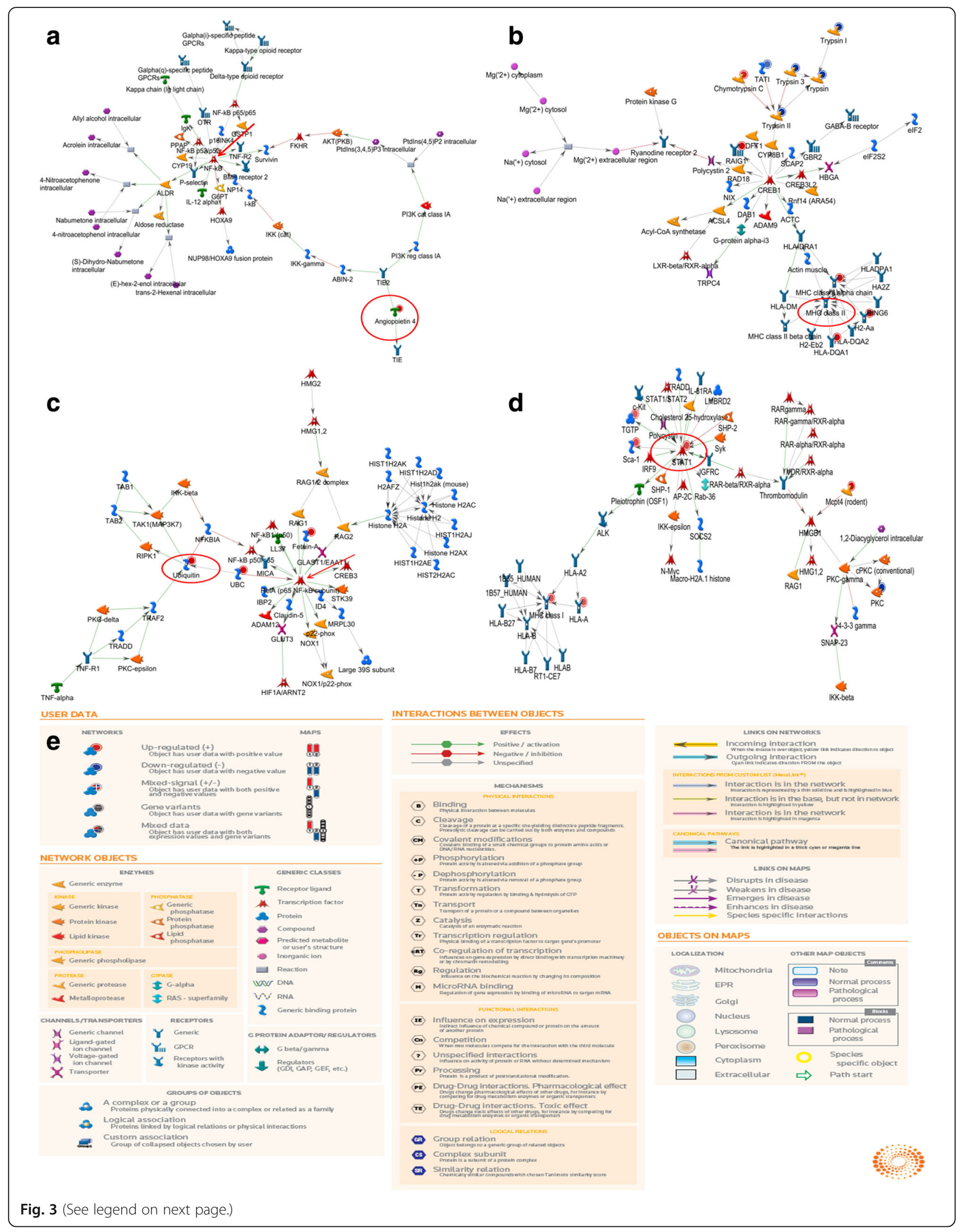


(See figure on previous page.)

Fig. 3 Biological networks generated by different groups. a Protein interaction networks of DEPs from four groups after taking the intersection; $\mathbf{b}$, $\mathbf{c}$ and $\mathbf{d}$ : protein interaction networks of DEPs from four groups after taking union (b: Major Histocompatibility Complex class IInetwork; c: Ubiquitination in Mediating the Cellular Stress Response; d: Interferon- $\gamma$-mediated signal transduction and response network); e Explanation of various symbols in the network map. The network of significantly differentially expressed proteins (ratio $\geq 1.32$ or $\leq 0.68$ fold) was analyzed by MetaCoreTM(version 6.18)software

categorized these proteins according to their molecular function and biological process using the GO database. 295 union proteins were selected and separated into 3 categories: biological processes (Fig. 2a), cellular component association (Fig. 2b), and molecular function (Fig. 2c).

In the biological process category, the results suggested that most of the DEPs participate in metabolic processes $(32.9 \%)$, cellular processes $(17.10 \%)$, biological regulation (12.6\%), and response to stimulus $(7.70 \%)$. In the cellular component analysis, most of the potential biomarkers are concentrated in the cell part $(32.80 \%)$, organelle (20.90\%), extracellular region (19.40\%), membrane (11.90\%) or macromolecular complex. In the molecular function analysis, the differentially expressed proteins were found to play a role in catalytic activity (34.60\%), binding (32.30\%), enzymatic activity (9.00\%) and structural molecule activity (8.30\%),suggesting that their related functions were important in the colon of mice.

On the basis of our findings, it could be concluded that the identified DEPs causing by SE, SEP and EFL 1 were mainly associated with the cellular part. The expression sites of them located within cells and organelles. G protein and Eph/Ephrin signal pathway were controlled jointly by SE and SEP. After processing, the extracts of SEP were mainly reflected in the process of cytoskeleton, glycolysis and gluconeogenesis.

\section{Pathway enrichment analysis and interaction network analysis}

MetaCore $^{\mathrm{TM}}$ (version 6.18) is an integrated software suite for functional analysis of experimental data. Differential pathways among $\mathrm{SE}, \mathrm{SEP}, \mathrm{EFL}_{1}$ and control were conducted according to the $P$ Value $(P<0.05)$. All the differential pathways were shown in Tables 3,4 and 5 .

Comparing with group 1(control), the pathways with higher activity were mainly related to the immune response, and also related to other physiological processes such as development and $G$ protein pathways; the dominant signaling pathways were interleukin signaling pathway, JAK/Stat et al.; the key proteins involved in multiple pathways contain STAT1, SERPINA3, G protein Rap1B and so on. Meanwhile, group $4\left(\mathrm{EFL}_{1}\right)$ showed that the physiological process with high activity was relatively simple, mainly focused on the immune response and development process. Interleukin signaling pathways, Ang/ Tie 2 and NF/kB were found to be the main signaling pathways and the key proteins involved were STAT1 and STAT5; compared with control, group 3 induced cytoskeleton remodeling, glycolysis and gluconeogenesis with higher activities, signaling pathways which contain a variety of major B-Raf pathways, epithelial cells to interstitial cell transition(EMT)-related signaling pathways, cell endocytosis, etc. and PDGF receptors, Ephrin receptors,in which STAT 1 was related to the key proteins.

A network was constructed by protein-protein interaction of the 295 significantly DEPs basing on Analyze Network Algorithm using MetaCore in Fig. 3 (A-D). (Tables 6 and 7).

Obviously, commonly pathways are mainly interleukinmediated signaling pathways, including IL-7, IL-15, IL-23 and other inflammatory factors both controlled by EFL and SE groups. We supposed that these inflammatory factors activate the interleukin signaling pathway, NF / kB signaling pathway, and then mediate intestinal mucosal barrier injure by up-regulating inflammatory proteins expression which resulting in inflammatory response. While there is no obvious interleukin-mediated inflammatory response in SEP group. Generally speaking, inflammatory response especially interleukin might be closely related to the attenuated mechanism of Semen Euphorbiae.

According to network analysis, four reliable functional networks were found and analyzed. After intersection of four groups, the main protein interaction network was multicellular organism regulation process (only Angiopoietin 4 is the down-regulated differentially expressed protein and NF-kB is a pivotal role which interacts with other

Table 6 Intersection of differentially expressed protein Networks

\begin{tabular}{|c|c|c|c|c|c|c|}
\hline Network & GO processes & $\begin{array}{l}\text { Total } \\
\text { nodes }\end{array}$ & $\begin{array}{l}\text { Seed } \\
\text { nodes }\end{array}$ & p-Value & zScore & gScore \\
\hline $\begin{array}{l}\text { Angiopoietin 4, NF-kB, ALDR, TIE2, } \\
\text { ATP }+ \text { Ptdlns }(4,5) P 2=A D P+ \\
\text { Ptdlns }(3,4,5) P 3\end{array}$ & $\begin{array}{l}\text { response to oxygen-containing compound }(70.6 \% ; 1.570 \mathrm{e}-16), \\
\text { regulation of multicellular organismal process }(76.5 \% ; 2.094 \mathrm{e}-15) \text {, } \\
\text { response to peptide }(47.1 \% ; 1.618 \mathrm{e}-14) \text {, response to stress }(82.4 \% \text {; } \\
2.570 \mathrm{e}-14) \text {, positive regulation of cellular process }(88.2 \% ; 3.104 \mathrm{e}-14)\end{array}$ & 51 & 1 & 0.00245 & 20.16 & 22.66 \\
\hline
\end{tabular}


Table 7 Union of differentially expressed protein Networks

\begin{tabular}{|c|c|c|c|c|}
\hline Network & GO processes & $p$-Value & zScore & gScore \\
\hline $\begin{array}{l}\text { Trypsin II, Chymotrypsin C, } \\
\text { Trypsin 3, TATI, RAIG1 }\end{array}$ & $\begin{array}{l}\text { antigen processing and presentation of peptide or polysaccharide } \\
\text { antigen via MHC class II }(27.3 \% ; 6.498 \mathrm{e}-17)\end{array}$ & $1.010 \mathrm{E}-21$ & 48.76 & 48.76 \\
\hline $\begin{array}{l}\text { Ubiquitin, Fetuin-A, UBC, RelA } \\
\text { (p65 NF-kB subunit), TRAF2 }\end{array}$ & $\begin{array}{l}\text { regulation of response to stress }(56.5 \% ; 6.254 \mathrm{e}-19) \text {, positive regulation } \\
\text { of NF-kappaB transcription factor activity }(28.3 \% ; 2.556 \mathrm{e}-17)\end{array}$ & 1.140E-05 & 14.33 & 44.33 \\
\hline $\begin{array}{l}\text { STAT1, TGTP, Mcpt4 (rodent), } \\
\text { Sca-1, Thrombomodulin }\end{array}$ & $\begin{array}{l}\text { interferon-gamma-mediated signaling pathway }(31.9 \% ; 8.694 \mathrm{e}-24) \text {, } \\
\text { response to interferon-gamma }(36.2 \% ; 1.175 \mathrm{e}-23)\end{array}$ & 2.970E-14 & 33.37 & 33.37 \\
\hline
\end{tabular}

proteins in the network most closely, Fig. 3a). DEPs which were taken together mainly participated in the protein interaction networks as shown in Fig. 3b, c and d. MHC II presents endogenous and exogenous antigenic peptides or antigenic polysaccharides (containing 10 differential proteins, the key point is $\mathrm{MHC}$ class II in Fig. 3b), stress response (containing 3 upregulation differential proteins, RelA/P65 and ubiquitin are the central part of network, Fig. 3c), $\gamma$ - Interferon - mediated signal transduction and response (containing 6 up-regulation,1 down-regulation differential proteins, as shown in Fig. 3d, STAT1 interacted closely with other proteins and play an important role in the networks).

It should be pointed out that Angiopoietin 4 is the only down-regulated differential expressed protein in the interaction network. Subsequently, STAT1 was found to be the key protein shared by the EFL ${ }_{1}, \mathrm{SEP}$ and SE tested groups, compared with the control group. A previous study has implied that the transcription factor $N F-k B$ (nuclear factor kappa B) plays a central role in the regulation of immune and inflammatory responses, as well as in control of cell apoptosis. These proteins participate in the regulation of a wide range of genes involved in immune, inflammatory and apoptosis function [21]. Although the relationship between Angiopoietin 4 and NF- $\mathrm{kB}$ has not been reported, according to the network, we could make the hypothesis that SE could increase Angiopoietin 4 and then activate NF-kB to make the body produce immune or inflammatory response. In addition, interferons (IFNs) are important cytokines that play essential roles in antiviral, antibacterial, antitumor and immunomodulatory activities. IFNs primarily signals through the JAK-STAT pathway leading to the activation of signal transducer and activator of STAT and subsequent transcription of target genes [22]. Based on the pathway analysis, IFN- $\gamma$ could activate STATs through JAK-STAT signal pathway to initiate CIITA (typeIItranscription activator) which as $\mathrm{MHC}$ IItrans activator, and then the expression of MHC II were up-regulated to produce immune response and immune regulation so that the mice have diarrhea symptoms after treated with SE group. For these reasons and hypothesis, western blot analysis was then conducted to validate the two differentially expressed proteins- STAT1 and Angiopoietin 4.

\section{Validation of differentially expressed proteins identified by proteomics}

Two proteins, STAT1 and Angiopoietin 4 identified DEPs with marked differences in expression determined by iTRAQ based quantitative analysis were selected to be verified by western blot analysis (Figs. 4 and 5). As depicted in Figs. 4 and 5 and Table 8, Angiopoietin 4 protein was significantly down-regulated in SEH, SEPH and EFLH groups as compared with control group $(p<0.05)$, the expression level of Ang4 in SEH was the lowest; and STAT1 was up-regulated in SEH, SEPH and EFLH groups, which levels were all higher than control group $(p<0.05)$. Moreover, the groups of low dose of SEL, SEPL and EFLL have no significant differences compared with the control. The results which were found by western blot is consistent with the findings in iTRAQ analysis. Both of Ang-4 and STAT1 expression levels in the mice colon tissue may be dose-dependent with the increase dose of SE and SEP.

It is well established that the angiopoietin (Ang) family of growth factors includes Ang1, Ang2, Ang3 and Ang4,

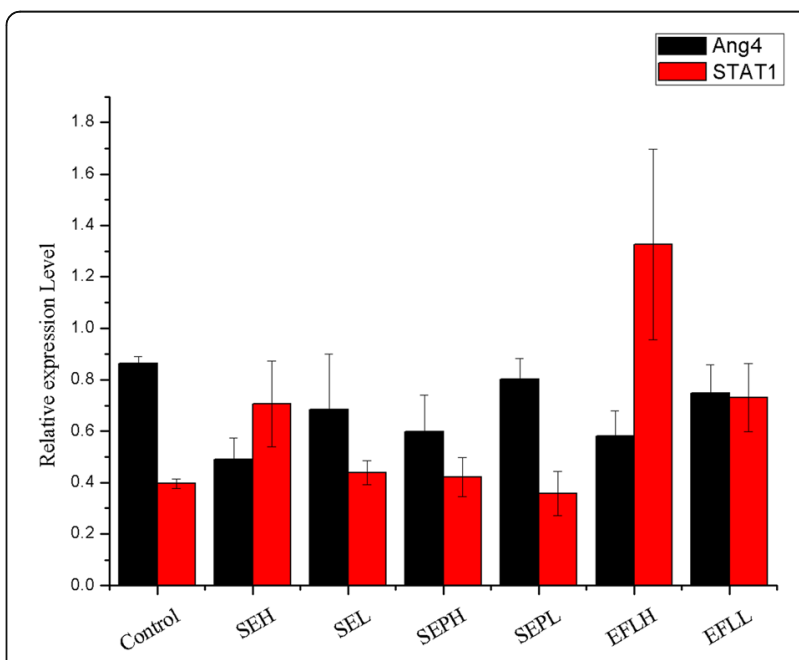

Fig. 4 Relative expression levels of Ang4 and STAT1were normalized to the $\beta$-actin which were quantified by densitometric analysis. These experiments were each conducted five times 


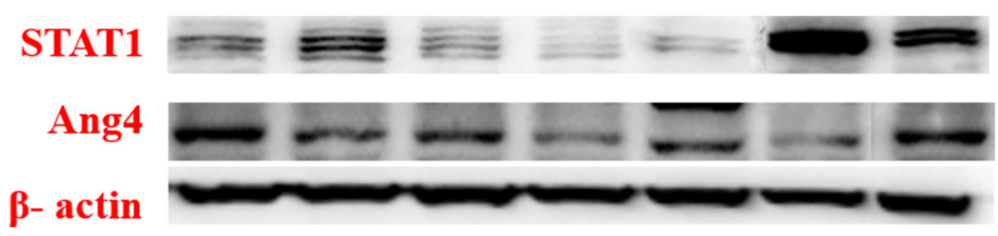

Fig. 5 Western blotting showing the changes in Ang4 and STAT1 level in mice intestine treated with different doses of SE, SEP and EFL 1 with respect to control-treated mice intestineNote:Internal reference:ß- actin,1.Control, 2.High-dose of SE (SEH, $1.5 \mathrm{ml} / 20 \mathrm{~g})$, 3.low-dose of SE (SEL, $0.5 \mathrm{ml} / 20 \mathrm{~g})$, 4. High-dose of SEP (SEPH, $1.0 \mathrm{ml} / 20 \mathrm{~g}$ ), 5. Low-dose of SEP (SEPL, $0.33 \mathrm{ml} / 20 \mathrm{~g})$, 6.High-dose of EFL $(E F L H, 20 \mathrm{mg} / 20 \mathrm{~g}), 7$ Low-dose of $\mathrm{EFL}_{1}$ (EFLL, $\left.10 \mathrm{mg} / 20 \mathrm{~g}\right)$

all of which bind to the endothelial receptor tyrosine kinase Tie2. Ang3 (mouse) and Ang4 (human) are interspecies orthologs. Tie2 [23] maintains the vascular integrity of mature vessels by enhancing endothelial barrier function and inhibiting apoptosis of endothelial cells. According to the pathway network analysis, as shown in Fig. 3a, we speculated that Semen Euphorbiae might inhibit the expression of Ang-4, which Tie-2 couldn't be activated, so that the steady state of endothelial cells was broken and the sensitivity of various inflammatory mediators increased, permeability, and thus promoted the occurrence of inflammatory response. The inhibition of Ang 4 by SEP group after processing was weakened comparing to SE group, resulting in lower diarrhea and inflammatory response.

STAT1 has been implicated as a mediator of biological responses to a variety of growth factors and cytokines, based on ligand-dependent tyrosine phosphorylation and activation. Stat1 is a functional transcription factor even in the absence of inducer-mediated activation, participating in the constitutive expression of some genes [24]. JAK2/ STAT pathway signaling is activated by a wide array of cytokines and growth factors leading to the stimulation of cell proliferation, differentiation, and apoptosis [25]. And it is an important way of signal transduction of inflammatory factors.

In addition to being involved in the main JAK2 / STAT signaling pathway, STAT1 could be activated by JAK2

Table 8 The relative expression of Ang4 and STAT1 in intestinal tissue of mice $(\bar{X} \pm S, n=5)$

\begin{tabular}{lll}
\hline groups & Ang4 & STAT1 \\
\hline Control & $0.865 \pm 0.027$ & $0.396 \pm 0.019$ \\
SEH & $0.489 \pm 0.084^{*}$ & $0.706 \pm 0.167^{*}$ \\
SEL & $0.683 \pm 0.218$ & $0.439 \pm 0.046$ \\
SEPH & $0.598 \pm 0.142^{*}$ & $0.421 \pm 0.076$ \\
SEPL & $0.803 \pm 0.080$ & $0.358 \pm 0.086$ \\
EFLH & $0.582 \pm 0.098^{*}$ & $1.326 \pm 0.372^{*}$ \\
EFLL & $0.749 \pm 0.111$ & $0.731 \pm 0.133$ \\
\hline
\end{tabular}

Note: *compared with control $(P<0.05)$ (non-receptor tyrosine) kinase, but also by inflammatory factors such as interleukin-6 (IL-6), tumor necrosis factor (TNF),growth factors such as interferon (IFN) [26], epidermal growth factor (EGF), platelet-derived growth factor (PDGF) and other signal activation.

As the up-regulated proteins induced by each group, STAT1 was induced by SEP group lower than the SE group so that we suspected that STAT 1 was most likely one of target proteins related to intestinal inflammation which might illustrate the attenuated mechanism of Semen Euphorbiae.

Both Ang-4 and STAT1 were surmised to be one of the target proteins inducing by Semen Euphorbiae.

\section{Conclusions}

This study used iTRAQ labeling followed by 2D-LCMS/MS for the quantitative proteomic analysis of intestine samples from KM mice with different groups and control to discover candidate biomarkers for attenuated mechanism of Semen Euphorbiae processing for the first time. These findings suggest that SE induced an inflammatory response, and activated the Interleukin signaling pathway, such as the Ang/Tie 2 and JAK2/ STAT signaling pathways, which may eventually contribute to injury result from intestinal inflammatory, while SEP could ease this injury by reducing STAT1 and activating Ang-4 which could reduce the inflammatory response. Taken together, these results not only provided a novel insight into attenuated mechanism of Semen Euphorbiae, which was marked by a number of DEPs that might be associated with intestinal inflammation, but also the first experimental evidence that the Angiopoietin 4 and STAT1 proteins might be two major candidate biomarkers in the attenuated of SE after processing based on proteomic investigation. Our findings suggest that this screening method has potential valuable in studying mechanism of processing. Future systematic studies will investigate how Semen Euphorbiae regulate the expression of these key proteins and illustrate the problem from a clinical point of view.

\section{Abbreviations}

2D-LC-MS/MS: Two-dimensional liquid chromatography-tandem mass spectrometry; ACN: Acetonitrile; Ang: Angiopoietin; CIITA: Typelltranscription 
activator; DEPs: Differentially expressed proteins; DTT: Dithiothreitol; EFL 1 : Euphorbiae Factor 1; EGF: Epidermal growth factor; Eph/ Ephrin: Erythropoientin-producing hepatocyte kinases/Eph receptor interacting proteins; GO: Gene ontology; IFN: Interferon; IgG: Immunoglobulin G; IL6: Interleukin-6; iTRAQ: Isobaric tags for relative and absolute quantitation; JAK2: Janus Kinase 2; LC: Liquid chromatography; NF-KB: Nuclear factor kappa B; PDGF: Platelet-derived growth factor; PSMs: Peptide-spectrum matches; PVDF: Polyvinylidene fluoride; SDS-PAGE: Sodium dodecyl sulfate polyacrylamide gel electrophoresis; SE: Semen Euphorbiae; SEP: Semen Euphorbiae Pulveratum; STAT1: Signal transducers and activators of transcription one; TCM: Traditional Chinese medicine: TNF: Tumor necrosis factor

\section{Acknowledgments}

Not applicable.

\section{Funding}

This work was sponsored by grants from NSFC projects (No. 81673597).

\section{Availability of data and materials}

Please contact author for data requests.

\section{Authors' contributions}

ZY carried out the preparations of Semen Euphorbiae and Semen Euphorbiae Pulveratum, participated in western blot and drafted the manuscript. ZXT carried out Proteomics extraction procedures. LWH and LSX participated in the design of the study and performed the statistical analysis. SZY and NRJ helped to draft the manuscript and perform the statistical analysis. WYZ and LSJ conceived of the study, and participated in its design and coordination and helped to draft the manuscript. All authors read and approved the final manuscript.

\section{Ethics approval and consent to participate}

All procedures employed were approved by Animal Ethical and Welfare Committee of Beijing University of Chinese Medicine.

\section{Consent for publication}

Not applicable.

\section{Competing interests}

All the authors declare that they have no competing interest.

\section{Publisher's Note}

Springer Nature remains neutral with regard to jurisdictional claims in published maps and institutional affiliations.

\section{Received: 24 October 2017 Accepted: 26 March 2018}

Published online: 17 April 2018

\section{References}

1. Shi QW, Su XH, Kiyota H. Chemlnform abstract: chemical and pharmacological research of the plants in genus Euphorbia. Chemlnform. 2008;108(10):4295-327.

2. Wang YS,Song GW,Zhang HW, et al. Analysis of semen euphorbiae frostlike powders by HPLC fingerprint. 2013;25 (17):10011-10014.

3. FUNG. Characterization of semen euphorbiae. Proceedings of the Society for Experimental Biology \& Medicine Society for Experimental Biology \& Medicine. 2011;128(1):75-80.

4. Wang $Z Y$, Kang H, Ji LL, et al. Proteomic characterization of the possible molecular targets of pyrrolizidine alkaloid isoline-induced hepatotoxicity. Environmental Toxicology \& Pharmacology. 2012;34(2):608-17.

5. Van SA, Renes J, van Delft JH, et al. Proteomics in the search for mechanisms and biomarkers of drug-induced hepatotoxicity. Toxicology in Vitro An International Journal Published in Association with Bibra. 2012; 26(3):373-85.

6. Wei J, Zhang F, Zhang Y, et al. Proteomic investigation of signatures for geniposide-induced hepatotoxicity. J Proteome Res. 2014;13(12):5724-33.

7. Witzmann FA, Grant RA. Pharmacoproteomics in drug development Pharmacogenomics Journal. 2003;3(2):69-76.

8. Su L, Cao L, Zhou R, et al. Identification of novel biomarkers for Sepsis prognosis via urinary proteomic analysis using iTRAQ labeling and 2D-LCMS/MS. PLoS One. 2013;8(1):e54237
9. Ye H, Sun L, Huang $X$, et al. A proteomic approach for plasma biomarker discovery with 8-plex iTRAQ labeling and SCX-LC-MS/MS. Mol Cell Biochem. 2010;343(1):91-9.

10. Caubet $\mathrm{C}$, Lacroix CS, Drube J, et al. Advances in urinary proteome analysis and biomarker discovery in pediatric renal disease. Pediatr Nephrol. 2010;25(1):27-35

11. Adolf W, Hecker E. Further new diterpene esters from the irritant and cocarcinogenic seed oil and latex of the caper spurge ( Euphorbia lathyris L.). Experientia. 1971;27(12):1393-4.

12. Zhu JJ, Wang YZ, Zhang C, et al. Determination of olein compositions in the petroleum ether extractant of semen euphorbiae by gas chromatogra phymass. Journal of Shandong University of Traditional Chinese Medicine. 2013; 37(5):438-41.

13. Zhu J, Zhang C, Wang Y, et al. Study on chemical constituents of petroleum ether Extractant of semen euphorbiae. Journal of Shandong University of Traditional Chinese Medicine. 2014;38(4):381-2,391.

14. Duan FP, Wang YZ, Li CX. Chemical composition and biological activity analysis of semen euphorbiae petroleum ether extracts. Journal of Chemical \& Pharmaceutical Research. 2014;6(5):745-9.

15. Bradford M. A rapid method for the quantification of microgram quantities of protein utilizing the principle of protein-dye binding. Anal Biochem. 1976;72(s 1-2):248-54

16. Sacute W, Niewski JR, et al. Universal sample preparation method for proteome analysis. Nat Methods. 2009;6(5):359-62.

17. Tam JC, Ko CH, Cheng Z, et al. Comprehensive proteomic analysis of a Chinese 2-herb formula (Astragali Radix and Rehmanniae Radix) on mature endothelial cells. Proteomics. 2014;14(17-18):2089-103.

18. Zhang K, Pan X, Zheng J, et al. Comparative tissue proteomics analysis of thoracic aortic dissection with hypertension using the iTRAQ technique. European journal of cardio-thoracic surgery : official journal of the European Association for Cardio-thoracic Surgery. 2015;47(3):431-8.

19. Ren W, Hou X, Wang Y, et al. Overgrazing induces alterations in the hepatic proteome of sheep (Ovis aries): an iTRAQ-based quantitative proteomic analysis. Proteome Sci. 2016;15(1):2.

20. Glen A, Gan CS, Hamdy FC, et al. iTRAQ-facilitated proteomic analysis of human prostate cancer cells identifies proteins associated with progression. J Proteome Res. 2008;7(3):897-907.

21. Gong YT, Wang XM. NF-kB and neurodegenerative disorder in central nervous system. Chinese Bulletin of Life Sciences. 2004;16(5):280-4.

22. Schindler C, Plumlee C. Inteferons pen the JAK-STAT pathway. Semin Cell Dev Biol. 2008;19(4):311.

23. Fukuhara S, Sako K, Minami T, et al. Differential function of Tie2 at cell|[ndash]|cell contacts and cell|[ndash]|substratum contacts regulated by angiopoietin-1. Nat Cell Biol. 2008;10(5):513-26.

24. Ramana CV, Chatterjee-Kishore $\mathrm{M}$, Nguyen $\mathrm{H}$, et al. Complex roles of Stat1 in regulating gene expression. Oncogene. 2000;19(21):2619-27.

25. Caldow MK,Cameron-Smith D.JAK/STAT Pathway.2012:495-497.

26. Sikorski K, Czerwoniec A, Bujnicki JM, et al. STAT1 as a novel therapeutical target in pro-atherogenic signal integration of IFNY, TLR4 and IL-6 in vascular disease. Cytokine Growth Factor Rev. 2011;22(4):211-9.

\section{Submit your next manuscript to BioMed Central and we will help you at every step:}

- We accept pre-submission inquiries

- Our selector tool helps you to find the most relevant journal

- We provide round the clock customer support

- Convenient online submission

- Thorough peer review

- Inclusion in PubMed and all major indexing services

- Maximum visibility for your research

Submit your manuscript at www.biomedcentral.com/submit
Biomed Central 